Cochrane Database of Systematic Reviews

\title{
Levonorgestrel intrauterine system for endometrial protection in women with breast cancer on adjuvant tamoxifen (Review)
}

Dominick S, Hickey M, Chin J, Su HI

Dominick S, Hickey M, Chin J, Su HI.

Levonorgestrel intrauterine system for endometrial protection in women with breast cancer on adjuvant tamoxifen.

Cochrane Database of Systematic Reviews 2015, Issue 12. Art. No.: CD007245.

DOI: 10.1002/14651858.CD007245.pub3.

www.cochranelibrary.com

Levonorgestrel intrauterine system for endometrial protection in women with breast cancer on adjuvant 
TABLE OF CONTENTS

HEADER

ABSTRACT

PLAIN LANGUAGE SUMMARY

SUMMARY OF FINDINGS

BACKGROUND

OBJECTIVES

METHODS

Figure 1.

Figure 2.

Figure 3.

RESULTS

Figure 4.

Figure 5.

Figure 6.

Figure 7.

Figure 8.

Figure 9.

DISCUSSION

AUTHORS' CONCLUSIONS

ACKNOWLEDGEMENTS

REFERENCES

CHARACTERISTICS OF STUDIES

DATA AND ANALYSES

Analysis 1.1. Comparison 1 LNG-IUS with endometrial surveillance versus endometrial surveillance alone, Outcome 1 Endometrial Polyps.

Analysis 1.2. Comparison 1 LNG-IUS with endometrial surveillance versus endometrial surveillance alone, Outcome 2 Endometrial Hyperplasia.

Analysis 1.3. Comparison 1 LNG-IUS with endometrial surveillance versus endometrial surveillance alone, Outcome 3 Endometrial Cancer.

Analysis 1.4. Comparison 1 LNG-IUS with endometrial surveillance versus endometrial surveillance alone, Outcome 4 Fibroids.

Analysis 1.5. Comparison 1 LNG-IUS with endometrial surveillance versus endometrial surveillance alone, Outcome 5 Abnormal Vaginal Bleeding or Spotting.

Analysis 1.6. Comparison 1 LNG-IUS with endometrial surveillance versus endometrial surveillance alone, Outcome 6 Breast Cancer Recurrence.

Analysis 1.7. Comparison 1 LNG-IUS with endometrial surveillance versus endometrial surveillance alone, Outcome 7 Breast Cancer-related Death.

ADDITIONAL TABLES

APPENDICES

WHAT'S NEW

HISTORY

CONTRIBUTIONS OF AUTHORS

DECLARATIONS OF INTEREST

SOURCES OF SUPPORT

DIFFERENCES BETWEEN PROTOCOL AND REVIEW

INDEX TERMS 
[Intervention Review]

\section{Levonorgestrel intrauterine system for endometrial protection in women with breast cancer on adjuvant tamoxifen}

Sally Dominick ${ }^{1}$, Martha Hickey ${ }^{2}$, Jason Chin ${ }^{3}$, H Irene Su 4

1Moores UCSD Cancer Center, University of California, San Diego, La Jolla, California, USA. 2The University of Melbourne, The Royal Women's Hospital, Melbourne, Australia. ${ }^{3}$ King Edward Memorial Hospital/SJOG Murdoch Hospital, Perth, Australia. ${ }^{4}$ Department of Reproductive Medicine, University of California, San Diego, La Jolla, California, USA

Contact address: $\mathrm{H}$ Irene Su, Department of Reproductive Medicine, University of California, San Diego, La Jolla, California, 92093, USA. hisu@ucsd.edu.

Editorial group: Cochrane Gynaecology and Fertility Group.

Publication status and date: New search for studies and content updated (no change to conclusions), published in Issue 12, 2015.

Citation: Dominick S, Hickey M, Chin J, Su HI. Levonorgestrel intrauterine system for endometrial protection in women with breast cancer on adjuvant tamoxifen. Cochrane Database of Systematic Reviews 2015, Issue 12. Art. No.: CD007245. DOI: 10.1002/14651858.CD007245.pub3.

Copyright (c) 2015 The Cochrane Collaboration. Published by John Wiley \& Sons, Ltd.

\section{A B S T R A C T}

\section{Background}

Adjuvant tamoxifen reduces the risk of breast cancer recurrence in women with oestrogen receptor-positive breast cancer. Tamoxifen also increases the risk of postmenopausal bleeding, endometrial polyps, hyperplasia, and endometrial cancer. The levonorgestrel-releasing intrauterine system (LNG-IUS) causes profound endometrial suppression. This systematic review considered the evidence that the LNGIUS prevents the development of endometrial pathology in women taking tamoxifen as adjuvant endocrine therapy for breast cancer.

\section{Objectives}

To determine the effectiveness and safety of levonorgestrel intrauterine system (LNG-IUS) in pre- and postmenopausal women taking adjuvant tamoxifen following breast cancer for the outcomes of endometrial and uterine pathology including abnormal vaginal bleeding or spotting, and secondary breast cancer events.

\section{Search methods}

We searched the following databases: Cochrane Menstrual Disorders and Subfertility Group Specialised Register (MDSG), Cochrane Breast Cancer Group Specialised Register (CBCG), Cochrane Central Register of Controlled Trials (CENTRAL), Cochrane Database of Abstracts of Reviews of Effects (DARE), The Cochrane Library, clinicaltrials.gov, The World Health Organisation International Trials Registry, ProQuest Dissertations \& Theses, MEDLINE, EMBASE, CINAHL (Cumulative Index to Nursing and Allied Health Literature), PsycINFO, Web of Science, OpenGrey, LILACS, PubMed, and Google. The final search was performed in October 2015.

\section{Selection criteria}

Randomised controlled trials of women with breast cancer on adjuvant tamoxifen that compared endometrial surveillance alone (control condition) versus the LNG-IUS with endometrial surveillance (experimental condition) on the incidence of endometrial pathology.

\section{Data collection and analysis}

Study selection, risk of bias assessment and data extraction were performed independently by two review authors. The primary outcome measure was endometrial pathology (including polyps, endometrial hyperplasia, or endometrial cancer) diagnosed at hysteroscopy or endometrial biopsy. Secondary outcome measures included fibroids, abnormal vaginal bleeding or spotting, breast cancer recurrence, and breast cancer-related deaths. The overall quality of evidence was rated using GRADE methods. 


\section{Main results}

Four randomised controlled trials involving 543 women were identified and are included in this review. In the included studies, the active treatment arm was the $20 \mu \mathrm{g} /$ day levonorgestrel-releasing intrauterine system (LNG-IUS) plus endometrial surveillance; the control arm was endometrial surveillance alone. In tamoxifen users, the LNG-IUS led to a reduction in the incidence of endometrial polyps over both a 12 -month period (Peto OR $0.22,95 \% \mathrm{Cl} 0.08$ to $0.64,2$ studies, $\mathrm{n}=212, \mathrm{I}^{2}=0 \%$ ) and over a long-term follow-up period ( 24 to 60 months) (Peto OR $0.22,95 \% \mathrm{Cl} 0.13$ to $0.39,4$ studies, $n=417, \mathrm{I}^{2}=0 \%$, moderate quality evidence). Also the LNG-IUS led to a reduction in the incidence of endometrial hyperplasia over a long-term follow-up period ( 24 to 60 months) (Peto OR $0.13,95 \% \mathrm{Cl} 0.03$ to 0.67 , four studies, $n=417, I^{2}=$ $0 \%$, moderate quality evidence). However, it should be noted that the number of events of endometrial hyperplasia was low ( $n=6)$. None of the trials were sufficiently powered to detect whether LNG-IUS leads to significant changes in the incidence of endometrial cancer in tamoxifen users. At 12 months of follow-up abnormal vaginal bleeding or spotting was more common in the LNG-IUS treatment group (Peto OR $7.26,95 \% \mathrm{Cl} 3.37$ to $15.66,3$ studies, $n=376, \mathrm{I}^{2}=0 \%$, moderate quality evidence). By 24 months of follow-up, abnormal vaginal bleeding or spotting occurred less frequently compared to 12 months of follow-up in the LNG-IUS treatment group but was still more common than the control group (Peto OR 2.72, 95\% Cl 1.04 to 7.10, 2 studies, $n=233, I^{2}=0 \%$, moderate quality evidence). By 60 months of follow-up, no cases of abnormal vaginal bleeding or spotting were reported in either group. The numbers of events for the following outcomes were low: fibroids ( $n=13)$, breast cancer recurrence $(n=18)$, and breast cancer-related deaths $(n=16)$. There was no evidence of a difference between the LNG-IUS treatment group and controls for these outcomes. The quality of the evidence was judged as moderate, due to limited sample sizes and low event rates for the outcome comparisons.

\section{Authors' conclusions}

The LNG-IUS reduces the incidence of benign endometrial polyps and endometrial hyperplasia in women with breast cancer taking tamoxifen. At 12 and 24 months of follow-up, the LNG-IUS increased abnormal vaginal bleeding or spotting among women in the treatment group compared to those in the control. There is no clear evidence from the available randomised controlled trials that the LNG-IUS prevents endometrial cancer in these women. There is no clear evidence from the available randomised controlled trials that the LNGIUS affects the risk of breast cancer recurrence or breast cancer-related deaths. Larger studies are necessary to assess the effects of the LNG-IUS on the incidence of endometrial cancer, and to determine whether the LNG-IUS might have an impact on the risk of secondary breast cancer events.

\section{PLAIN LANGUAGE SUMMARY}

\section{Levonorgestrel intrauterine system (LNG-IUS) for endometrial protection in women with breast cancer taking tamoxifen to prevent recurrence}

\section{Review question:}

Cochrane authors investigated whether the levonorgestrel-releasing intrauterine system (LNG-IUS) can reduce the risk of endometrial polyps, abnormal thickening of the lining of the uterus and endometrial cancer in women taking tamoxifen following breast cancer. The review also investigated whether use of the LNG-IUS influences the risk of abnormal vaginal bleeding or spotting, fibroids, breast cancer recurrence or death in women taking tamoxifen following breast cancer.

\section{Background:}

Tamoxifen is commonly used by women to reduce the risk of breast cancer recurrence. Tamoxifen can also cause abnormal changes to the lining of the uterus (endometrium), including polyps and cancer. The LNG-IUS is a uterine device that releases the synthetic hormone levonorgestrel into the endometrium and causes marked endometrial suppression. As levonorgestrel is a progestin, and many breast cancers are progesterone-sensitive, it is important to study the safety of the LNG-IUS in breast cancer survivors.

\section{Study characteristics:}

We included four randomised controlled trials involving 543 women. The studies took place in the United Kingdom, Turkey, Egypt and Hong Kong, and the primary outcome in all studies was abnormal changes in the lining of the uterus. Three studies reported on the outcome of fibroids. Three studies reported on abnormal vaginal bleeding or spotting. Two studies reported on the outcomes of breast cancer recurrence, and three studies reported on the outcomes of breast cancer-related death. The evidence is current to October 2015.

\section{Key results:}

This review suggests that the LNG-IUS can reduce the risk of endometrial polyps and endometrial hyperplasia over a long-term followup period ( 24 to 60 months) in women taking tamoxifen following breast cancer. At 12 and 24 months of follow-up, more women in the LNG-IUS group experienced abnormal vaginal bleeding or spotting. However by 60 months of follow-up, no abnormal vaginal bleeding or spotting was reported in either group. There were insufficient data to show whether there is any effect on incidence of endometrial cancer (a cancer originating in glandular tissue), fibroids, breast cancer recurrence, or breast cancer-related death.

\section{Quality of the evidence:}


The quality of the evidence was judged as moderate, due to limited sample sizes and low event rates for the outcome comparisons. Larger studies are necessary to assess the effects of the LNG-IUS on the incidence of endometrial cancer, and the impact of the LNG-IUS on the risk of secondary breast cancer events. 
SUMMARY OF FINDINGS

Summary of findings for the main comparison. The LNG-IUS with endometrial surveillance compared to endometrial surveillance alone for endometrial protection in women with breast cancer on adjuvant tamoxifen

The LNG-IUS with endometrial surveillance compared to endometrial surveillance alone for endometrial protection in women with breast cancer on adjuvant tamoxifen

Patient or population: endometrial protection in women with breast cancer on adjuvant tamoxifen

Setting: hospital, outpatient clinic

Intervention: LNG-IUS with endometrial surveillance

Comparison: endometrial surveillance alone

\begin{tabular}{|c|c|c|c|c|c|c|}
\hline \multirow[t]{2}{*}{ Outcomes } & \multicolumn{2}{|c|}{ Illustrated comparative risks ${ }^{\star}(95 \% \mathrm{Cl})$} & \multirow{2}{*}{$\begin{array}{l}\text { Relative effect } \\
(95 \% \mathrm{Cl})\end{array}$} & \multirow{2}{*}{$\begin{array}{l}\text { № of partici- } \\
\text { pants } \\
\text { (studies) }\end{array}$} & \multirow{2}{*}{$\begin{array}{l}\text { Quality of the } \\
\text { evidence } \\
\text { (GRADE) }\end{array}$} & \multirow[t]{2}{*}{ Comments } \\
\hline & Assumed Risk & Corresponding Riks & & & & \\
\hline $\begin{array}{l}\text { Endometrial Polyps } \\
\text { follow up: range } 24 \text { months to } 60 \\
\text { months }\end{array}$ & \multicolumn{2}{|l|}{ Moderate } & $\begin{array}{l}\text { OR } 0.22 \\
\text { (0.13 to } 0.39)\end{array}$ & $\begin{array}{l}417 \\
\text { (4 RCTs) }\end{array}$ & $\begin{array}{l}\oplus \oplus \oplus \ominus \\
\text { MODERATE } 1\end{array}$ & \\
\hline \multirow{2}{*}{$\begin{array}{l}\text { Endometrial Hyperplasia } \\
\text { follow up: range } 24 \text { months to } 60 \\
\text { months }\end{array}$} & \multicolumn{2}{|l|}{ Moderate } & \multirow{2}{*}{$\begin{array}{l}\text { OR } 0.13 \\
(0.03 \text { to } 0.67)\end{array}$} & \multirow{2}{*}{$\begin{array}{l}417 \\
(4 \mathrm{RCTs})\end{array}$} & \multirow{2}{*}{$\begin{array}{l}\oplus \oplus \oplus \odot \\
\text { MODERATE } 1\end{array}$} & \\
\hline & 28 per 1000 & $\begin{array}{l}4 \text { per } 1000 \\
(1 \text { to } 19)\end{array}$ & & & & \\
\hline $\begin{array}{l}\text { Endometrial Cancer } \\
\text { follow up: range } 24 \text { months to } 60 \\
\text { months }\end{array}$ & Moderate & & not estimable & $\begin{array}{l}154 \\
(2 \mathrm{RCTs})\end{array}$ & $\begin{array}{l}\oplus \oplus \oplus \odot \\
\text { MODERATE } 1\end{array}$ & \\
\hline \multirow{2}{*}{$\begin{array}{l}\text { Fibroids } \\
\text { follow up: range } 12 \text { months to } 24 \\
\text { months }\end{array}$} & Moderate & & \multirow{2}{*}{$\begin{array}{l}\text { OR } 0.48 \\
(0.16 \text { to } 1.46)\end{array}$} & \multirow{2}{*}{$\begin{array}{l}314 \\
(3 \mathrm{RCTs})\end{array}$} & \multirow{2}{*}{$\begin{array}{l}\oplus \oplus \oplus \odot \\
\text { MODERATE } 1\end{array}$} & \\
\hline & 58 per 1000 & $\begin{array}{l}29 \text { per } 1000 \\
(10 \text { to } 82)\end{array}$ & & & & \\
\hline \multirow{2}{*}{$\begin{array}{l}\text { Abnormal Vaginal Bleeding or Spotting } \\
\text { follow up: } 12 \text { months }\end{array}$} & Moderate & & \multirow{2}{*}{$\begin{array}{l}\text { OR } 7.26 \\
\text { (3.37 to } 15.66 \text { ) }\end{array}$} & \multirow{2}{*}{$\begin{array}{l}376 \\
\text { (3 RCTs) }\end{array}$} & \multirow{2}{*}{$\begin{array}{l}\oplus \oplus \oplus \ominus \\
\text { MODERATE } 1\end{array}$} & \\
\hline & 17 per 1000 & 113 per 1000 & & & & \\
\hline
\end{tabular}




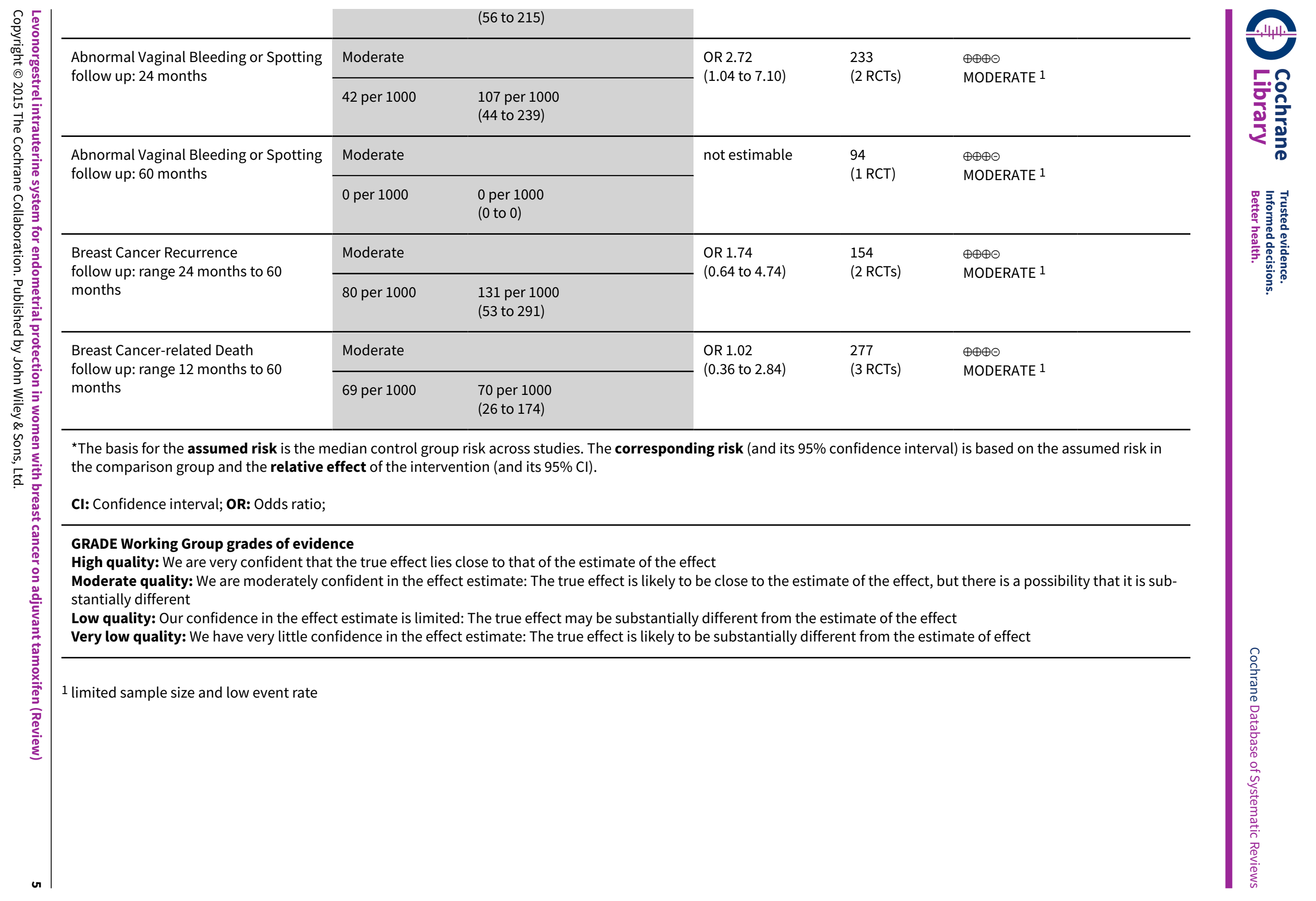




\section{B A C K G R O U N D}

\section{Description of the condition}

Breast cancer is the most common cancer in women, affecting up to one in eight women in developed countries (www.cancer.org). Most of these cancers express the oestrogen receptor (ER) and progesterone receptor (PR). Adjuvant treatment in most cases includes anti-oestrogen therapy. For most premenopausal and many postmenopausal women this is with the selective ER modulator tamoxifen. Five-year treatment with tamoxifen is associated with a $41 \%$ relative reduction in the annual risk of relapse and a 34\% relative reduction in the annual risk of death among those women with ER-positive breast cancer (EBCTCG 2005). Additionally, ten-year treatment with tamoxifen is associated with significant reductions in the risk of breast cancer recurrence, breast cancer mortality and overall mortality in women with ER-positive breast cancer (Davies 2013).

Tamoxifen is a selective ER modulator (SERM), which inhibits growth of breast cancer by competitive antagonism at the ER level. However, it has partial agonist effects on the skeletal system, lipid metabolism, the vagina, and the uterus. This oestrogenic effect in the uterus may promote the development of endometrial polyps, uterine fibroids, and endometrial hyperplasia (Cohen 2004; Kedar 1994) and causes a two-fold increase in the relative risk of endometrial cancer (Van Leeuwen 1994). These effects appear to be largely confined to postmenopausal women. Premenopausal women do not appear to have an increased risk of endometrial cancer while taking tamoxifen (ACOG 2006; Davies 2013). Despite this adverse endometrial profile for tamoxifen, for most women with breast cancer the benefits of taking tamoxifen for 5 to 10 years outweigh the risks. However, benign and malignant uterine pathology in tamoxifen users is a significant clinical problem (Coates 2007).

\section{Description of the intervention}

The contraceptive levonorgestrel intrauterine system (LNG-IUS) releases $20 \mu \mathrm{g}$ of levonorgestrel daily from a central core. Systemic concentrations of levonorgestrel are low and most of the progestogen is delivered to the endometrial cavity (Xiao 1990), where it causes profound suppression and decidualisation of the endometrium and glandular atrophy (Scommegna 1970).

\section{How the intervention might work}

Because of the profound anti-proliferative effect, the LNG-IUS is thought to reduce the risk of endometrial hyperplasia and endometrial cancer, and may be effective in treating established endometrial hyperplasia. The LNG-IUS has been used in women with breast cancer taking tamoxifen as a way of preventing endometrial proliferation. However, the safety of the LNG-IUS following oestrogen or progesterone receptor-positive breast cancer is unclear. A case control study from Finland suggested the LNG-IUS is associated with an increased risk with breast cancer (Lyytinen 2009). Small observational studies suggest that the LNGIUS does not adversely impact breast cancer prognosis (Trinh 2008).

\section{Why it is important to do this review}

This systematic review evaluated all available data from randomised controlled trials to assess the effectiveness of the LNG-IUS in preventing the development of endometrial pathology (polyps, hyperplasia, and cancer) in pre- and postmenopausal women taking adjuvant tamoxifen following breast cancer. Additionally, it is important to determine the effect of the LNGIUS in regards to developing fibroids, abnormal vaginal bleeding or spotting and secondary breast cancer events.

\section{O B JECTIVES}

To determine the effectiveness and safety of levonorgestrel intrauterine system (LNG-IUS) in pre- and postmenopausal women taking adjuvant tamoxifen following breast cancer for the outcomes of endometrial and uterine pathology including abnormal vaginal bleeding or spotting, and secondary breast cancer events.

\section{METHODS}

\section{Criteria for considering studies for this review}

Types of studies

Randomised controlled trials (RCTs) were eligible for inclusion. Quasi-randomised and non-randomised studies were excluded.

\section{Types of participants}

Pre- and postmenopausal women with breast cancer on adjuvant tamoxifen were eligible for inclusion. Women were excluded if they had any of the following conditions: contraindications to the LNGIUS, evidence of recurrent breast cancer prior to LNG-IUS insertion, or history of malignant disease other than breast cancer.

\section{Types of interventions}

Comparisons of the LNG-IUS combined with endometrial surveillance (experimental condition) versus endometrial surveillance alone (control condition).

\section{Types of outcome measures}

\section{Primary outcomes}

1. Endometrial polyps

2. Endometrial hyperplasia

3. Endometrial cancer

\section{Secondary outcomes}

4. Fibroids

5. Abnormal vaginal bleeding or spotting

\section{6 . Breast cancer recurrence}

\section{Breast cancer-related death}

\section{Search methods for identification of studies}

Using a search strategy developed in consultation with the Trials Search Coordinator for the Cochrane Menstrual Disorders and Subfertility Group (MDSG), we searched the following databases for all published and unpublished RCTs that compared the LNGIUS with endometrial surveillance versus endometrial surveillance alone, without language restrictions. 


\section{Electronic searches}

The searches were conducted in October 2015 and designed for the following databases: the Cochrane Menstrual Disorders and Subfertility Group Specialised Register (MDSG), see Appendix 1; Cochrane Breast Cancer Group Specialised Register (CBCG), see Appendix 2; Cochrane Central Register of Controlled Trials (CENTRAL), see Appendix 3; Cochrane Database of Abstracts of Reviews of Effects (DARE); The Cochrane Library, see Appendix 4; clinicaltrials.gov; The World Health Organisation International Trials Registry; ProQuest Dissertations \& Theses; MEDLINE (1946 to October 2015), see Appendix 5; EMBASE (1980 to October 2015), see Appendix 6; CINAHL (Cumulative Index to Nursing and Allied Health Literature) (1982 to October 2015), see Appendix 7; PsycINFO, see Appendix 8; Web of Science; OpenGrey; LILACS; PubMed (1946 to
October 2015), see Appendix 9; and Google. The search strategies for databases without appendices used similar terms as the MDSG and PubMed search strategies.

\section{Searching other resources}

We searched references of relevant systematic reviews and RCTs.

\section{Data collection and analysis}

\section{Selection of studies}

Studies were selected in accordance with the described criteria. Two review authors (SD and HIS) independently and in a standardised method assessed eligibility of the studies retrieved from the search, see Figure 1. Disagreement was resolved by consensus.

Figure 1. Study flow diagram

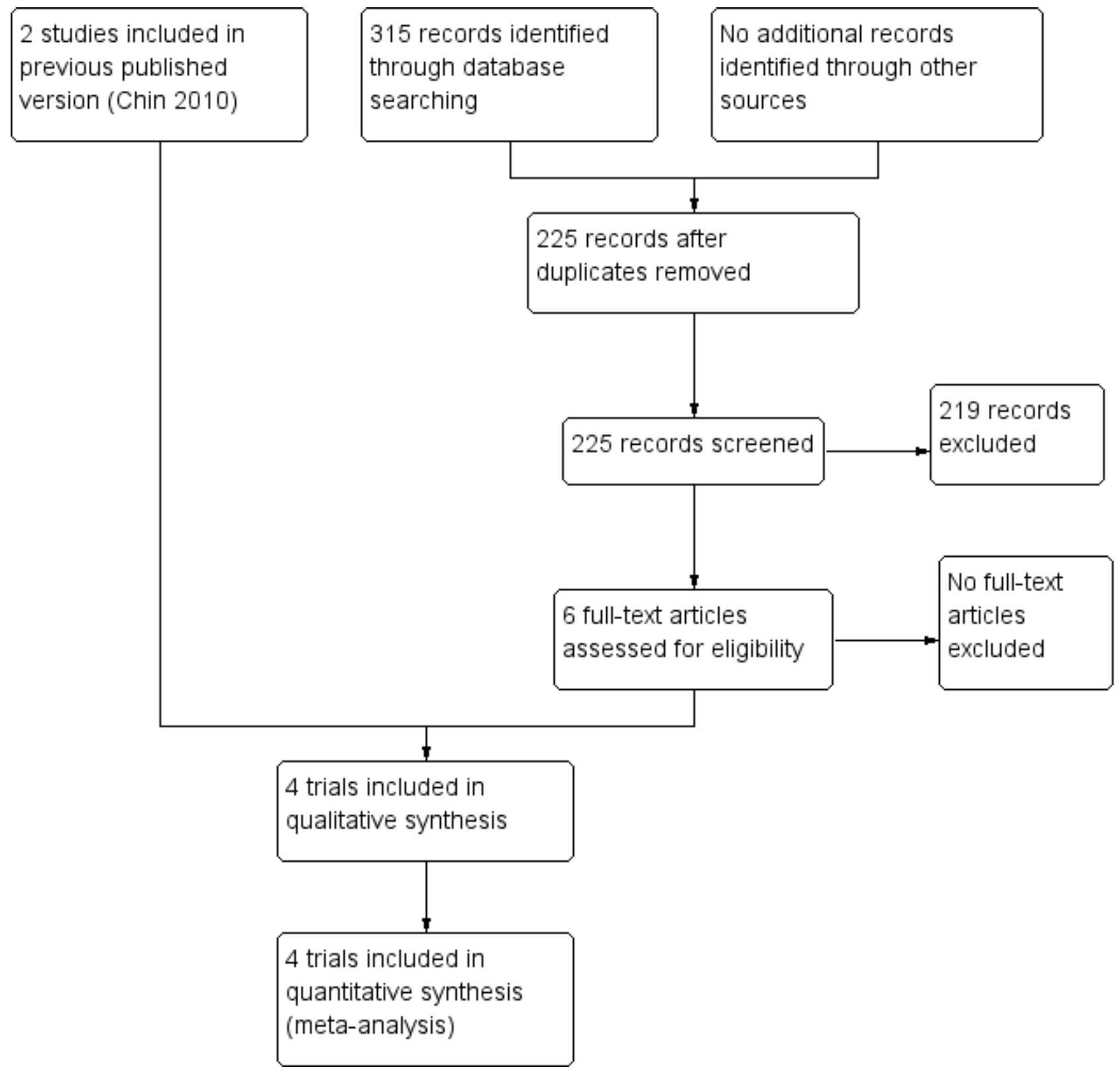




\section{Data extraction and management}

All data were extracted independently by two authors (SD and HIS) using forms designed according to the Cochrane guidelines (Higgins 2011). For each included trial, information was collected regarding the location of the study, methods of the study (as per risk of bias assessment checklist), the participants (age range, eligibility criteria), the nature of the interventions, and data relating to the outcomes specified above.

\section{Assessment of risk of bias in included studies}

The risk of bias for all studies that were deemed eligible for the review was assessed independently by two review authors (SD and HIS) using the Cochrane 'Risk of bias' assessment tool (Higgins 2011). Discrepancies were resolved by discussion. Trials were screened and analysed for the following risk of bias criteria.
1. Selection bias (random sequence generation and allocation concealment)

2. Performance bias (blinding of participants and personnel)

3. Detection bias (blinding of outcome assessment)

4. Attrition bias (incomplete outcome data)

5. Reporting bias (selective reporting)

6. Other bias

Each domain was assigned a high, low or unclear risk of bias rating. This information is presented in 'Risk of bias' tables (see Figure 2; Figure 3) and the text of the review.

Figure 2. Risk of bias graph: review authors' judgements about each risk of bias item presented as percentages across all included studies

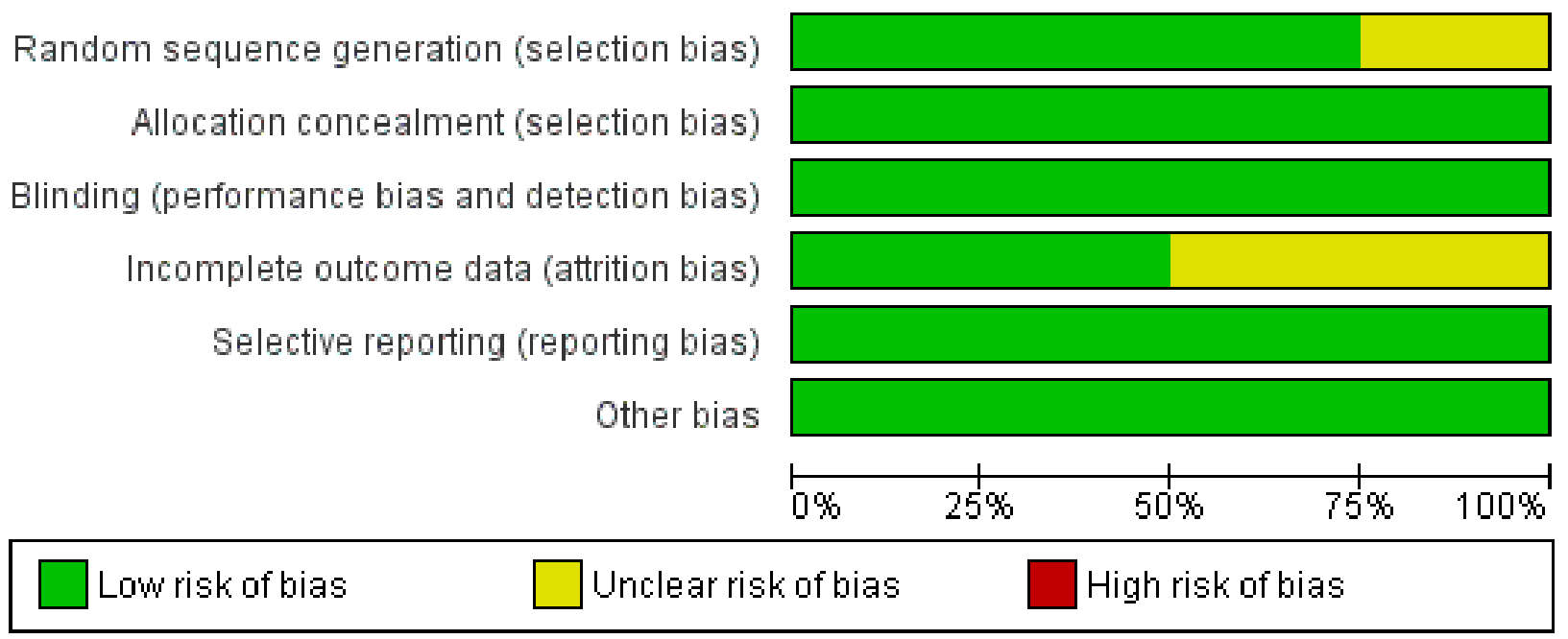


Figure 3. Risk of bias summary: review authors' judgements about each risk of bias item for each included study

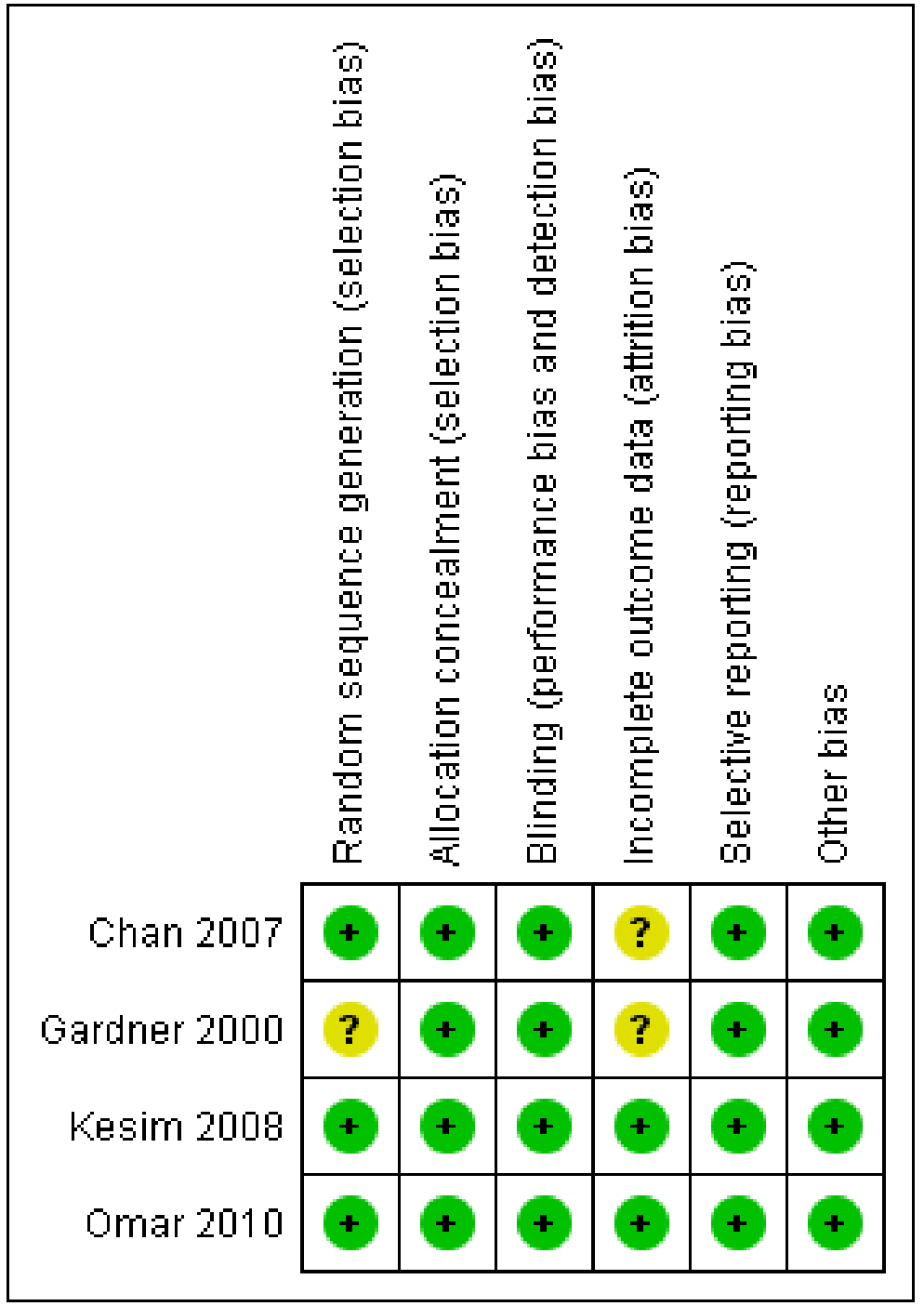

\section{Measures of treatment effect}

For dichotomous data (all the outcome measures in this review), results for each study were expressed as Peto odds ratios (Peto OR) with $95 \%$ confidence intervals $(\mathrm{Cl})$ and combined for meta-analysis with Review Manager 5 software using a fixed-effect model. The Peto method was selected because it performs well when events are very rare (Higgins 2011).

\section{Unit of analysis issues}

No unit of analysis issues were identified due to the nature of the data generated.

\section{Dealing with missing data}

The data were analysed on a intent-to-treat basis. If there had been missing data, we would have sought further information directly from the authors of the RCTs. Where no additional information was forthcoming, we analysed only the available data.

\section{Assessment of heterogeneity}

Heterogeneity (variation) between the results of different studies was examined by inspecting the scatter in the data points on a graph and the overlap in their Cls; and, more formally, by considering the $\mathrm{I}^{2}$ statistic and the $\mathrm{Chi}^{2}$ test $\mathrm{P}$ value. We would have interpreted a low $\mathrm{P}$ value (or a large $\mathrm{Chi}^{2}$ statistic relative to its number of degrees of freedom) as providing evidence of heterogeneity of intervention effects (a variation in effect estimates beyond chance). We would have interpreted the $I^{2}$ statistic, in conjunction with consideration of the magnitude and direction of the effects seen, as follows:

- $0 \%$ to $40 \%$, might not be important;

- $30 \%$ to $60 \%$, may represent moderate heterogeneity;

- $50 \%$ to $90 \%$, may represent substantial heterogeneity;

- $75 \%$ to $100 \%$, considerable heterogeneity.

\section{Assessment of reporting biases}

To minimise the potential impact of reporting biases, the authors conducted a comprehensive search for eligible articles and were 
alert for potential duplication of data. If 10 or more studies were included in an analysis, funnel plots would have been constructed to detect reporting biases.

\section{Data synthesis}

We pooled the results statistically for each comparison (endometrial polyps, endometrial hyperplasia, endometrial cancer, fibroids, abnormal vaginal bleeding or spotting, breast cancer recurrence and breast cancer-related death). The meta-analysis was carried out using Review Manager 5. We used the fixed effect method of synthesising the data for the combined analysis in accordance with the guidelines of the Cochrane Menstrual Disorders and Subfertility Group. We had no continuous data to consider; however, if we had had such data we would have used mean differences (MDs) or standardised mean differences (SMDs). If a large degree of heterogeneity had been detected, a randomeffects model would have been considered.

\section{Subgroup analysis and investigation of heterogeneity}

We did not pre-specify any subgroups for analysis and due to the nature of our findings neither a post hoc subgroup analysis nor an investigation of heterogeneity was required.

\section{Sensitivity analysis}

We planned to conduct the following sensitivity analyses for the primary outcomes:

- Eligibility was restricted to studies without high risk of bias

- A random-effects model had been adopted

- The summary effect measure was relative risk rather than Peto odds ratio.

\section{Overall quality of the body of evidence: Summary of findings table}

We generated a summary of findings table using GRADEpro software. This table evaluated the overall quality of the body of evidence for the review outcomes (endometrial polyps, endometrial hyperplasia, endometrial cancer, fibroids, abnormal vaginal bleeding or spotting, breast cancer recurrence and breast cancer-related death) using GRADE criteria: study limitations (i.e., risk of bias); consistency of effect; imprecision; indirectness and publication bias. Judgments about the quality of evidence (high, moderate or low) were justified, documented and incorporated into reporting of results for each outcome.

\section{RE S U L T S}

\section{Description of studies}

\section{Results of the search}

The electronic search was run in October 2015 and a total of 315 references were retrieved: $M D S G=16 ; C B C G=8 ; C E N T R A L=5$; DARE $=0$; The Cochrane Library = 6; clinicaltrials.gov $=1$; The World Health Organisation International Trials Registry $=1$; ProQuest Dissertations \& Theses $=2 ;$ MEDLINE $=54 ;$ EMBASE $=162 ;$ CINAHL $=37$; Web of Science $=8 ;$ PsycINFO $=1 ;$ OpenGrey $=0 ;$ LILACS = 7; PubMed = 6; and Google = 1. From those, we identified six potential studies, which were read in full; two of these six studies were included in the previously published review. No additional reference was retrieved from the manual search. See Figure 1 for details of the screening and selection process. See Characteristics of included studies; Table 1; Table 2; Table 3; Table 4 for detailed information.

\section{Included studies}

\section{Study design and setting}

The searches identified four randomised controlled trials for consideration in this review (Chan 2007; Gardner 2000; Kesim 2008; Omar 2010). These trials took place in Egypt (Omar 2010), Turkey (Kesim 2008), United Kingdom (Gardner 2000), and Hong Kong (Chan 2007). The Gardner 2000 and Chan 2007 trials published longterm follow-up of their trials (Gardner et al, 2009 and Wong et al, 2013 respectively).

\section{Participants}

The trials included 543 pre- and postmenopausal women with breast cancer on adjuvant tamoxifen; 273 women in the treatment group and 270 women in the control group.

\section{Interventions}

All four trials compared endometrial surveillance plus the LNGIUS, which releases $20 \mu \mathrm{g} /$ day of the synthetic progestogen levonorgestrel, to endometrial surveillance alone. The Chan 2007 trial (follow up: 60 months) compared endometrial surveillance alone versus endometrial surveillance plus the LNG-IUS insertion before the commencement of tamoxifen in pre- and postmenopausal women. The Gardner 2000 trial (follow up: 48 months) compared endometrial surveillance alone versus endometrial surveillance with insertion of the LNG-IUS in postmenopausal women who had been taking adjuvant tamoxifen treatment for at least one year. The Kesim 2008 trial (follow up: 36 months) compared endometrial surveillance alone versus endometrial surveillance with insertion of the LNG-IUS in postmenopausal women who had been taking adjuvant tamoxifen treatment for more than one year. The Omar 2010 trial (follow up: 24 months) compared endometrial surveillance alone versus endometrial surveillance with insertion of the LNG-IUS before the commencement of tamoxifen in pre- and postmenopausal women who required postoperative adjuvant tamoxifen.

\section{Outcomes}

All four trials reported endometrial polyps diagnosed at hysteroscopy with endometrial biopsy (Chan 2007; Gardner 2000; Kesim 2008; Omar 2010).

All four trials reported endometrial hyperplasia diagnosed at hysteroscopy with endometrial biopsy (Chan 2007; Gardner 2000; Kesim 2008; Omar 2010).

Two of the four trials reported no cases of endometrial cancer (Chan 2007; Gardner 2000).

Three of the four trials reported fibroids (Chan 2007; Gardner 2000; Omar 2010).

Three of the four trials reported abnormal vaginal bleeding or spotting (Chan 2007; Kesim 2008; Omar 2010).

Two of the four trials reported breast cancer recurrence (Chan 2007; Gardner 2000). 
Three of the four trials reported breast cancer-related death (Chan 2007; Gardner 2000; Omar 2010).

\section{Excluded studies}

There were no excluded studies.

\section{Risk of bias in included studies}

See Figure 2 and Figure 3 for detailed information.

\section{Allocation}

Three trials were assessed as low risk of selection bias related to sequence generation as all used computer generated random number series for allocation (Chan 2007; Kesim 2008; Omar 2010). One trial did not describe the sequence generation method used and was rated as unclear risk of selection bias related to sequence generation (Gardner 2000).

All trials were rated as low risk of selection bias related to allocation concealment as all used pre-prepared, serially-numbered sealed envelopes (Chan 2007; Gardner 2000; Kesim 2008; Omar 2010).

\section{Blinding}

All trials were rated as low risk of detection and performance bias as the pathologists (i.e., outcome assessors) were blinded (Chan 2007; Gardner 2000; Kesim 2008; Omar 2010). Even though the provider and participant were not blinded given the clinical intervention (insertion of the LNG-IUS), the blinding of providers and participants is considered unlikely to influence the outcomes.

\section{Incomplete outcome data}

Two trials were judged to be at low risk of attrition bias as the majority of randomised participants were included in the final analyses (Kesim 2008; Omar 2010). For both trials, there were no evidence of differences in baseline data between women who completed and did not complete the study.

One trial was judged as unclear risk of attrition bias (Chan 2007). At 12 months of follow-up, 16/129 (12\%) participants (7 in control group and 9 in treatment group) were lost to follow-up or dropped out. At 60 months of follow-up, 35/129 (27\%) participants (17 in the control group and 18 in the treatment group) were lost to follow-up.

One trial was judged as unclear risk of attrition bias (Gardner 2000). At 12 months of follow-up, 23/122 (19\%) of participants ( 6 in control group and 17 in treatment group) were lost to follow-up or dropped out. There were no evidence of differences in baseline data between women who completed and did not complete the study; hence the 12 months follow-up data are at low risk of attrition bias. However, the 24, 36 and 48 months follow-up data are considered at high risk of attrition bias due to the high rate of attrition. At 24 months of follow-up, 62/122 (51\%) of participants were lost to follow-up or dropped out. At 36 months of follow-up, 83/122 (68\%) of participants were lost to follow-up or dropped out. At 48 months of follow-up, 107/122 (88\%) of participants were lost to follow-up or dropped out.

\section{Selective reporting}

All four trials were considered at low risk of reporting bias (Chan 2007; Gardner 2000; Kesim 2008; Omar 2010). Due to the small number of included studies (less than 10), it was not considered appropriate to construct funnel plots to detect publication bias.

\section{Other potential sources of bias}

No other potential sources of bias were identified.

\section{Effects of interventions}

See: Summary of findings for the main comparison The LNGIUS with endometrial surveillance compared to endometrial surveillance alone for endometrial protection in women with breast cancer on adjuvant tamoxifen

See: Summary of findings table 1 LNG-IUS with endometrial surveillance compared to endometrial surveillance alone for endometrial protection in women with breast cancer on adjuvant tamoxifen.

\section{LNG-IUS with endometrial surveillance versus endometrial surveillance alone}

Primary outcomes

\subsection{Endometrial polyps}

At short-term follow-up (12 months), the pooled data from two trials (Chan 2007; Gardner 2000) suggested a reduction in the incidence of endometrial polyps in the LNG-IUS users group (2.0\%) compared to endometrial surveillance alone (11.8\%) (Peto OR 0.22, $95 \% \mathrm{Cl} 0.08$ to 0.64 , two RCTS, $\mathrm{n}=212, \mathrm{I}^{2}=0 \%$ ) (Analysis 1.1, Figure 4). 
Figure 4. Forest plot of comparison: 1 LNG-IUS with endometrial surveillance versus endometrial surveillance alone, outcome: 1.1 Endometrial Polyps.

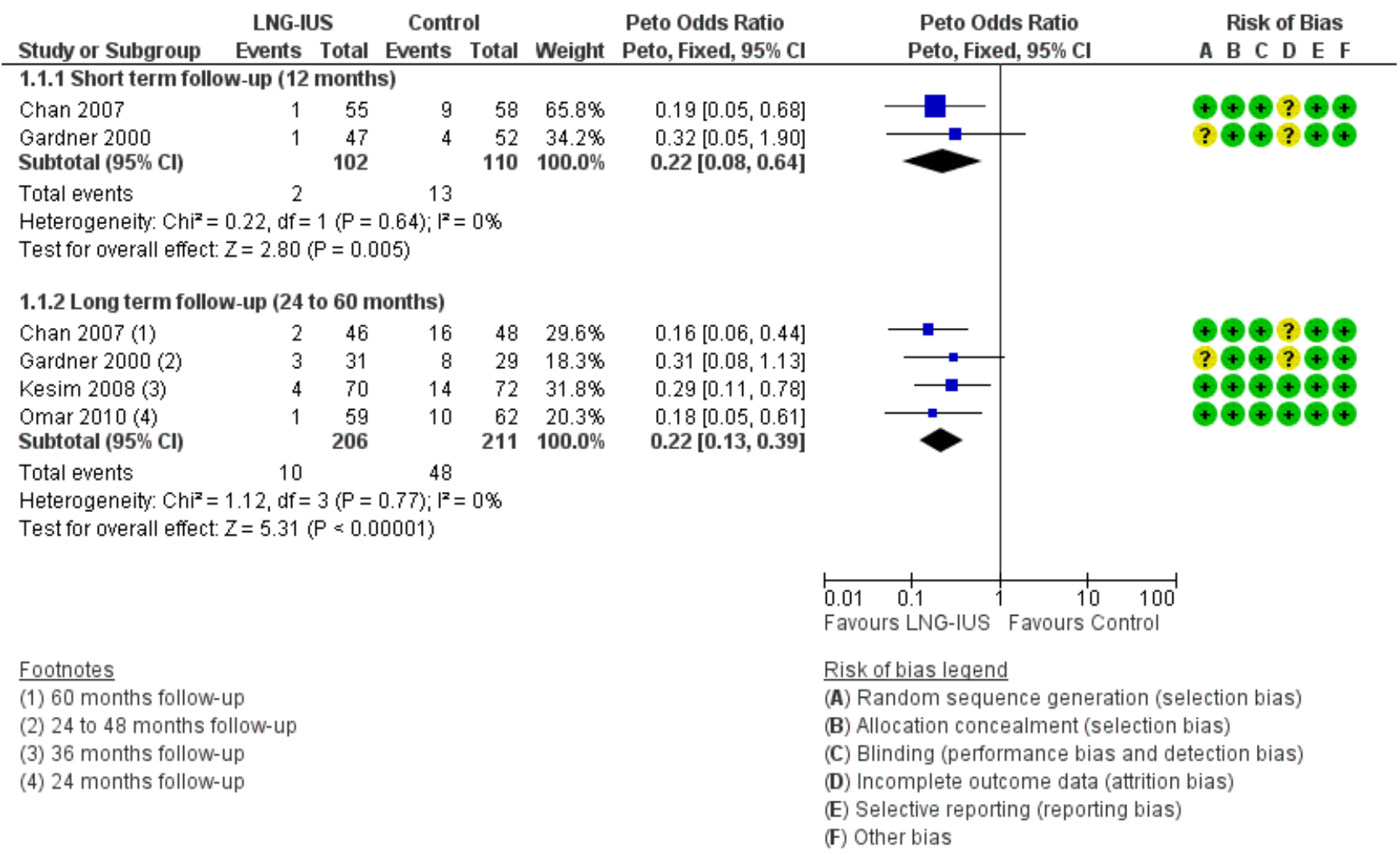

At long-term follow-up (24 to 60 months), the pooled data from all four trials (Chan 2007; Gardner 2000; Kesim 2008; Omar 2010) suggested a reduction in the incidence of endometrial polyps in the LNG-IUS users group (4.9\%) compared to endometrial surveillance alone (22.7\%) (Peto OR $0.22,95 \% \mathrm{Cl} 0.13$ to 0.39 , four RCTs, $\mathrm{n}=417$, $\mathrm{I}^{2}=0 \%$, moderate quality evidence) (Analysis 1.1,Figure 4).

\subsection{Endometrial hyperplasia}

At long-term follow-up (24 to 60 months), the pooled data from all four trials (Gardner 2000; Chan 2007; Kesim 2008; Omar 2010) showed only six cases of endometrial hyperplasia in the control group, which suggests a reduction in the incidence of endometrial hyperplasia in the LNG-IUS users compared to the control (Peto OR $0.13,95 \% \mathrm{Cl} 0.03$ to 0.67 , four RCTs, $n=417$, moderate quality evidence) (Analysis 1.2, Figure 5).

Figure 5. Forest plot of comparison: 1 LNG-IUS with endometrial surveillance versus endometrial surveillance alone, outcome: 1.2 Endometrial Hyperplasia.

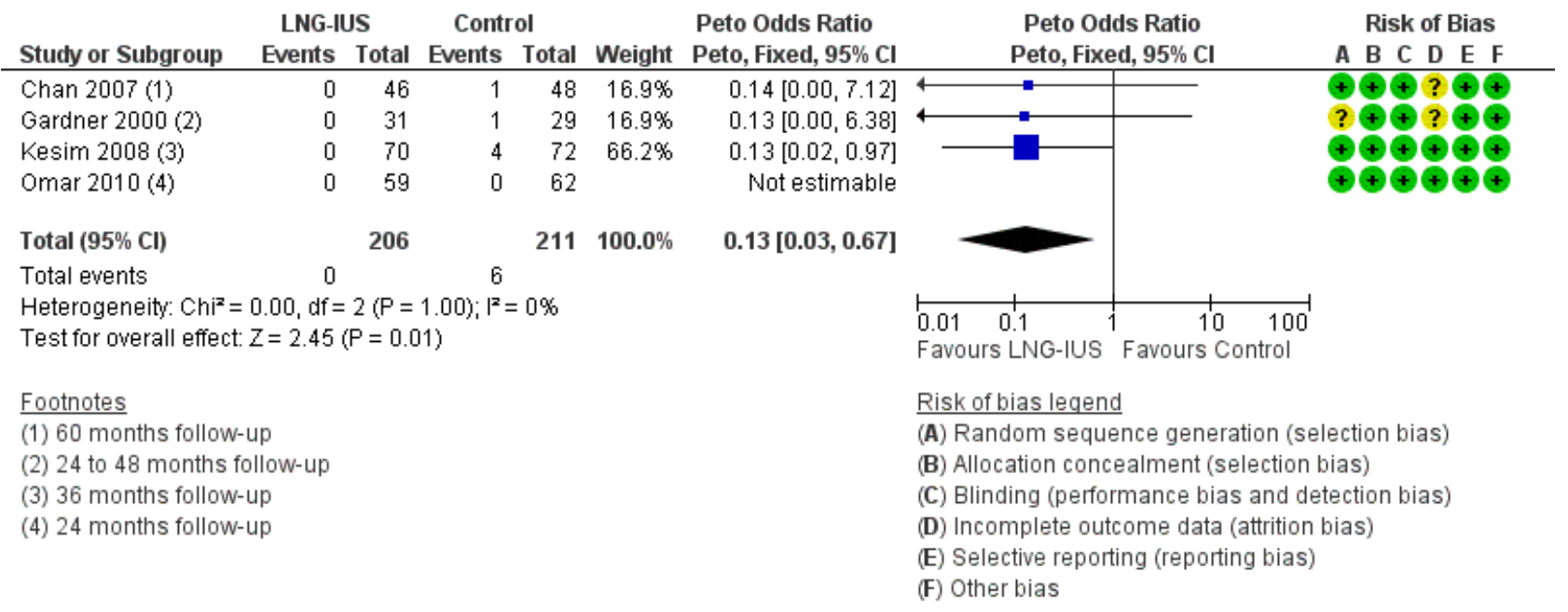




\subsection{Endometrial cancer}

The included studies reported no cases of endometrial cancer. Hence, we could not calculate statistics for the endometrial cancer outcome.

\section{Secondary outcomes}

\subsection{Fibroids}

Pooled data from three trials (Chan 2007; Gardner 2000; Omar 2010) showed no evidence of a difference in the incidence of fibroids in LNG-IUS users (2.6\%) compared to the control group with endometrial surveillance (5.6\%) (Peto OR $0.48,95 \% \mathrm{Cl} 0.16$ to 1.46 , three RCTs, $\mathrm{n}=314, \mathrm{I}^{2}=0 \%$, moderate quality evidence) (Analysis 1.4, Figure 6).

\section{Figure 6. Forest plot of comparison: 1 LNG-IUS with endometrial surveillance versus endometrial surveillance} alone, outcome: 1.4 Fibroids.

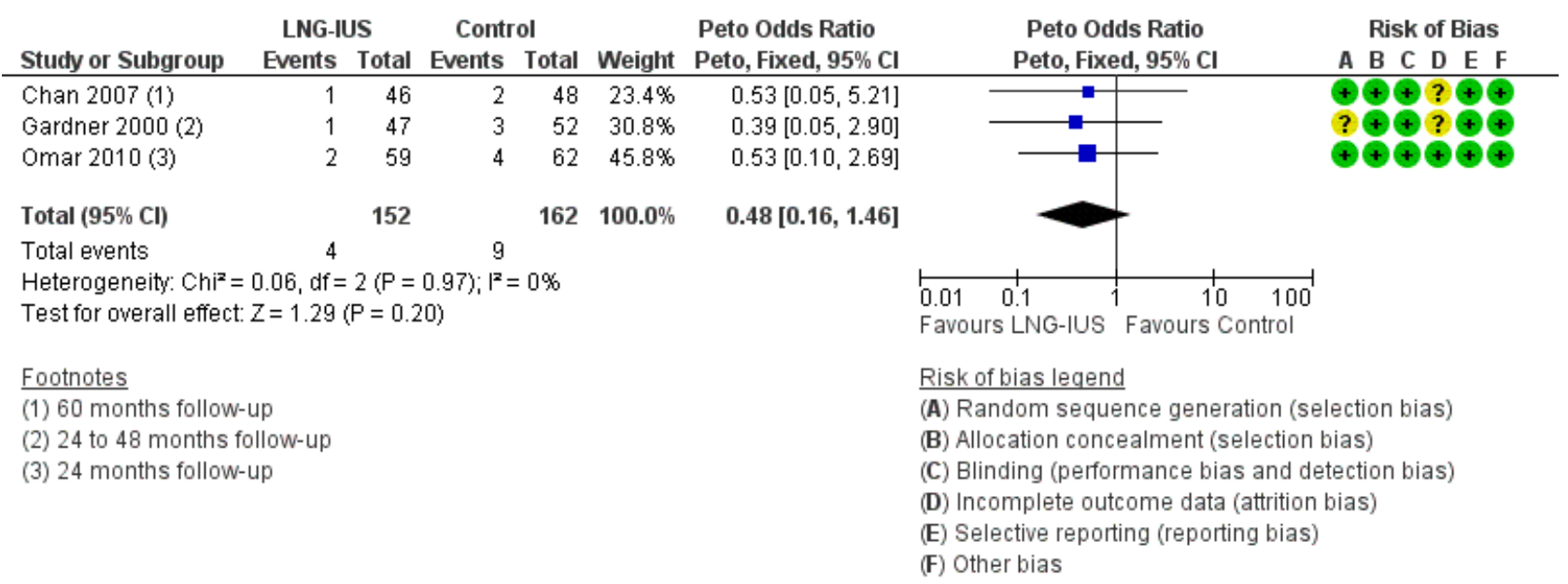

\subsection{Abnormal vaginal bleeding or spotting}

At 12 months of follow-up, three trials reported on abnormal vaginal bleeding or spotting in the LNG-IUS and control groups (Chan 2007; Kesim 2008; Omar 2010), and at 24 months of follow-up two of these trials (Chan 2007; Omar 2010) reported on abnormal vaginal bleeding or spotting. Only 1 trial (Chan 2007) reported on findings at 45 and 60 months of follow-up At 12 months of follow-up, there was more abnormal vaginal bleeding or spotting in the LNG-IUS treatment group (15.2\%) compared to endometrial surveillance alone (1.6\%) (Peto OR 7.26, 95\% Cl 3.37 to 15.66 , three RCTs, $n=376, I^{2}=0 \%$, moderate quality evidence) (Analysis 1.5 , Figure 7). At 24 months of follow-up, abnormal vaginal bleeding or spotting was reduced but still higher in the LNG-IUS group (11.4\%) compared to the control (4.2\%) (Peto OR 2.72, 95\% Cl 1.04 to 7.10 , two RCTs, $n=233, \mathrm{I}^{2}=0 \%$, moderate quality evidence) (Analysis 1.5, Figure 7). By 45 and 60 months of follow-up, no cases of abnormal vaginal bleeding or spotting were reported in either group (Analysis 1.5, Figure 7). 
Figure 7. Forest plot of comparison: 1 LNG-IUS with endometrial surveillance versus endometrial surveillance alone, outcome: 1.5 Abnormal Vaginal Bleeding or Spotting.

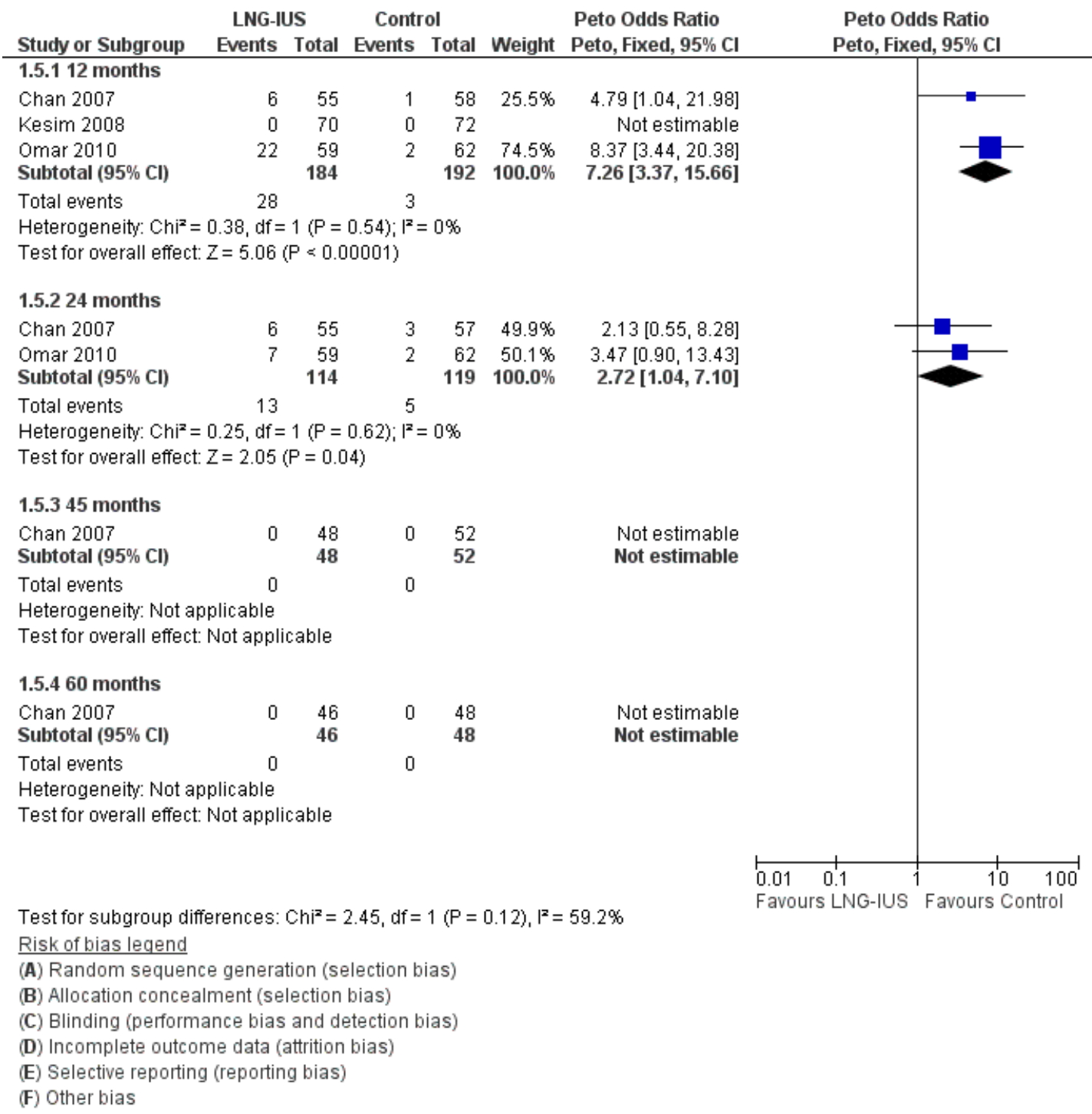

Risk of Bias A B C D E F

$+\odot+?+\odot$ $+\oplus+\oplus+$

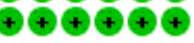

$\bullet+\oplus ?+\oplus$ $\odot \odot \odot \odot \odot \odot$ control group (9.1\%) with endometrial surveillance (Peto OR 1.74, $95 \% \mathrm{Cl} 0.64$ to 4.74 , two RCTs, $n=154, I^{2}=0 \%$, moderate quality evidence) (Analysis 1.6, Figure 8) (Chan 2007; Gardner 2000).

Pooled data from two trials showed no evidence of a difference in breast cancer recurrence in LNG-IUS users (14.3\%) compared to the 
Figure 8. Forest plot of comparison: 1 LNG-IUS with endometrial surveillance versus endometrial surveillance alone, outcome: 1.6 Breast Cancer Recurrence.

\begin{tabular}{|c|c|c|c|c|c|c|c|c|}
\hline \multirow[b]{2}{*}{ Study or Subgroup } & \multicolumn{2}{|c|}{ LNG-IUS } & \multicolumn{2}{|c|}{ Control } & \multirow[b]{2}{*}{ Weight } & \multirow{2}{*}{$\begin{array}{l}\text { Peto Odds Ratio } \\
\text { Peto, Fixed, 95\% Cl }\end{array}$} & \multirow{2}{*}{$\begin{array}{l}\text { Peto Odds Ratio } \\
\text { Peto, Fixed, 95\% Cl }\end{array}$} & Risk of Bias \\
\hline & Events & Total & Events & Total & & & & A B C D E F \\
\hline Chan 2007 (1) & 10 & 46 & 6 & 48 & $87.2 \%$ & $1.91[0.65,5.57]$ & & $\oplus+\oplus ? \oplus+$ \\
\hline Gardner 2000 (2) & 1 & 31 & 1 & 29 & $12.8 \%$ & $0.93[0.06,15.32]$ & & $? \oplus \odot ? \oplus \oplus$ \\
\hline Total $(95 \% \mathrm{Cl})$ & & 77 & & 77 & $100.0 \%$ & $1.74[0.64,4.74]$ & & \\
\hline Total events & 11 & & 7 & & & & & \\
\hline $\begin{array}{l}\text { Heterogeneity: } \mathrm{Chi}^{2}= \\
\text { Test for overall effect }\end{array}$ & $\begin{array}{l}0.22, \mathrm{df}= \\
Z=1.09(\end{array}$ & $\begin{array}{l}1(P= \\
P=0.2\end{array}$ & $\begin{array}{l}0.64) ; 1^{2}= \\
8)\end{array}$ & $=0 \%$ & & & $\begin{array}{lll}0.01 & 0.1 & 1\end{array}$ & \\
\hline $\begin{array}{l}\text { Footnotes } \\
\text { (1) } 60 \text { months follow } \\
\text { (2) } 24 \text { to } 48 \text { months } f\end{array}$ & up & & & & & & $\begin{array}{l}\text { Risk of bias legend } \\
\text { (A) Random sequence genera } \\
\text { (B) Allocation concealment (s } \\
\text { (C) Blinding (performance bia } \\
\text { (D) Incomplete outcome data } \\
\text { (E) Selective reporting (reporti } \\
\text { (F) Other bias }\end{array}$ & $\begin{array}{l}\text { lection bias) } \\
\text { bias) } \\
\text { tection bias) } \\
\text { bias) }\end{array}$ \\
\hline
\end{tabular}

\subsection{Breast cancer-related death}

Pooled data from three trials showed no evidence of a difference in breast cancer-related deaths in LNG-IUS users (5.8\%) compared to the control group (5.7\%) with endometrial surveillance (Peto OR $1.02,95 \% \mathrm{Cl} 0.36$ to 2.84 , three RCTs, $\mathrm{n}=277, \mathrm{I}^{2}=0 \%$, moderate quality evidence) (Analysis 1.7, Figure 9) (Chan 2007; Gardner 2000; Omar 2010).

Figure 9. Forest plot of comparison: 1 LNG-IUS with endometrial surveillance versus endometrial surveillance alone, outcome: 1.7 Breast Cancer-related Death.

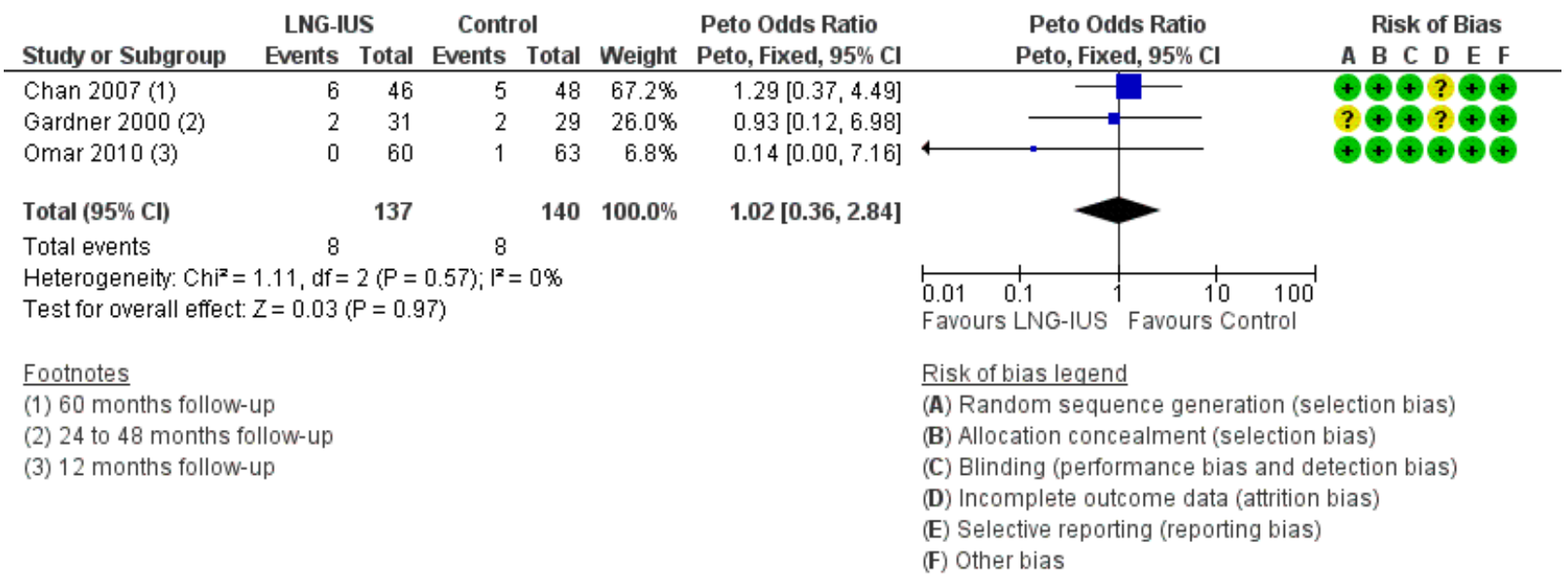

\section{Sensitivity analyses}

We did not conduct the planned sensitivity analysis by risk of bias, because risk of bias was similar across the included studies.

We conducted the planned sensitivity analyses by statistical model and effect estimate. When switching the pooled estimate from Peto odds ratio to Mantel-Haenszel risk ratio and fixed or random effects for all outcomes, only the pooled estimate for the endometrial hyperplasia outcome changed, to show no evidence of a difference between the groups (RR fixed effect $0.19,95 \% \mathrm{Cl} 0.03$ to 1.15 , four RCTs, $\mathrm{n}=417$ ).

\section{DISCUSSION}

\section{Summary of main results}

See Summary of findings table 1.

This review included four randomised controlled trials that compared endometrial protection by the $20 \mathrm{\mu g} /$ day levonorgestrelreleasing intrauterine system (LNG-IUS) plus endometrial surveillance versus endometrial surveillance alone in women with breast cancer on adjuvant tamoxifen. The pooled data from the included studies found that the LNG-IUS led to a significant reduction in the incidence of endometrial polyps over a 12-month period and a long-term follow-up period (24 to 60 months) among women with breast cancer taking tamoxifen. Also the LNG-IUS led to a reduction in endometrial hyperplasia over a long-term follow-up 
period (24 to 60 months). The pooled data showed there was more abnormal vaginal bleeding or spotting in the LNG-IUS treatment group compared to the control at 12 months and 24 months of follow-up. However, there was a gradual reduction of abnormal vaginal bleeding or spotting from 12 to 24 months, and no bleeding or spotting in either group was reported at 45 or 60 months of follow-up. Additionally, there was no difference in the odds of fibroids ( $n=13)$, breast cancer recurrence $(n=18)$, and breast cancer-related deaths $(n=16)$ between the LNG-IUS treatment groups and controls. Since none of the studies reported cases of endometrial cancer, there were insufficient data to show an effect on the incidence of endometrial cancer.

\section{Overall completeness and applicability of evidence}

All four included studies (Chan 2007; Gardner 2000; Kesim 2008; Omar 2010) used the 'gold standard' of hysteroscopy and endometrial biopsy to diagnose endometrial pathology. Endometrial pathology prior to randomisation was excluded by hysteroscopy and endometrial biopsy; any endometrial pathology detected at baseline was treated. Endometrial pathology was the primary end point for all four studies. However, the timing of the primary end point assessment varied by study, ranging from 12 to 60 months.

While the four included studies differed in patient selection, inclusion criteria, secondary outcomes assessed, and overall study design (see Characteristics of included studies), adequate information was provided to answer the review question. The findings of this review provide evidence that the LNG-IUS prevents endometrial polyps and endometrial hyperplasia in women with breast cancer using tamoxifen. However, the data are insufficient to suggest that the LNG-IUS protects tamoxifen users from endometrial cancer.

\section{Quality of the evidence}

Using the GRADE system, the quality of the evidence for all study outcomes (i.e., endometrial polyps, endometrial hyperplasia, endometrial cancer, fibroids, abnormal vaginal bleeding or spotting, breast cancer recurrence and breast cancer-related death) was judged as moderate (see Summary of findings table 1). For all four studies, evidence was downgraded by one level because of limited sample sizes and low event rates for the study outcomes. Also it should be noted that none of the studies were sufficiently powered to address whether the LNG-IUS protects women on tamoxifen against endometrial cancer.

Further, a potential limitation of this review is the inclusion of both pre- and postmenopausal women in two of the included studies (Chan 2007; Omar 2010). This may have underestimated the effect of the levonorgestrel intrauterine system (LNG-IUS) in preventing endometrial pathology in postmenopausal women.

\section{Potential biases in the review process}

No potential biases were identified by the authors in the review process. Based on the comprehensive literature search and included search terms, we are confident that all relevant studies were identified and included in this review.

\section{Agreements and disagreements with other studies or reviews}

No other reviews were identified.

\section{AUTHORS' CONCLUSIONS}

\section{Implications for practice}

The LNG-IUS is moderately effective in reducing the risk of benign polyps in tamoxifen users. This is clinically significant since polyps may be symptomatic and when identified require removal which is likely to include a general anaesthetic and hysteroscopy. There is no evidence that the LNG-IUS prevents endometrial polyps in women who are not taking tamoxifen. There is evidence that the LNGIUS reduces the incidence of endometrial hyperplasia in women on tamoxifen following breast cancer. There is no evidence that the LNG-IUS protects against, or reduces the risk of, endometrial cancer in women on tamoxifen following breast cancer. Abnormal vaginal bleeding or spotting is increased for up to 24 months after LNG-IUS insertion in tamoxifen users compared to tamoxifen users not using the LNG-IUS, which may increase the need for invasive diagnostic procedures to exclude hyperplasia and malignancy. The safety of the LNG-IUS in women with breast cancer in terms of prognosis, breast cancer recurrence, or breast cancer-related deaths is uncertain.

\section{Implications for research}

Studies powered to detect changes in the incidence of endometrial cancer in women with breast cancer using tamoxifen are needed. Since endometrial cancer risks with tamoxifen are limited to postmenopausal women, future studies should focus on this population. Larger studies are also necessary to assess whether the LNG-IUS may impact prognosis after breast cancer or secondary breast cancer events. Current level one evidence demonstrating that aromatase inhibitors are more effective in preventing recurrence of ER positive breast cancer has changed prescribing patterns of endocrine therapy and is likely to make the clinical problem of endometrial stimulation with tamoxifen and use of the LNG-IUS to lower this risk less clinically significant.

\section{ACKNOWLEDGEMENTS}

We thank the Cochrane Menstrual Disorders and Subfertility Group for providing us with the search strategy, support, and advice for this review. In particular, we wish to acknowledge Helen Nagels, Marion Showell and Jane Marjoribanks for their contribution to this review. 


\section{RE F E R E N C E S}

\section{References to studies included in this review}

Chan 2007 \{published data only\}

* Chan SSC, Tam WH, Yeo W, Yu MMY, Ng DPS, Wong AWY, et al. A randomised controlled trial of prophylactic levonorgestrel intrauterine system in tamoxifen treated women. BJOG 2007;114(12):1510-5.

Wong AWY, Chan SSC, Yeo W, Yu MY, Tam WH. Prophylactic use of levonorgestrel-releasing intrauterine system in women with breast cancer treated with tamoxifen: a randomized controlled trial. Obstetrics and Gynecology 2013;121(5):943-50.

Gardner 2000 \{published data only\}

* Gardner FJE, Konje JC, Abrams KR, Brown LJR, Khanna S, Al-Azzawi F, et al. Endometrial protection from tamoxifenstimulated changes by a levonorgestrel-releasing intrauterine system: a randomised controlled trial. Lancet 2000;356(9243):1711-7.

Gardner FJE, Konje JC, Bell SC, Abrams KR, Brown LJ, Taylor DJ, Habiba M. Prevention of tamoxifen induced endometrial polyps using levonorgestrel releasing intrauterine system: Long-term follow-up of a randomised control trial. Gynecologic Oncology 2009;114(3):452-6.

\section{Kesim 2008 \{published data only\}}

Kesim MD, Aydin Y, Atis A, Mandiraci G. Long-term effects of the levonorgestrel-releasing intrauterine system on serum lipids and the endometrium in breast cancer patients taking tamoxifen. Climacteric 2008;11(3):252-7.

Omar 2010 \{published data only\}

Omar H, Elkhayat W, Aboulkasem M. The use of levonorgestrelreleasing intrauterine system in prevention of endometrial pathology in women with breast cancer treated with tamoxifen. The International Journal of Medicine 2010;3(1):327-330.

\section{Additional references}

\section{ACOG 2006}

ACOG Committee Opinion No 336. Tamoxifen and uterine cancer. Obstetrics and Gynecology 2006;107(6):1475-8.

\section{Coates 2007}

Coates AS, Keshaviah A, et al. Five years of letrozole compared with tamoxifen as initial adjuvant therapy for postmenopausal women with endocrine-responsive early breast cancer: update of study BIG 1-98. Journal of Clinical Oncology 2007;10;25(5):486-92.

\section{Cohen 2004}

Cohen I. Endometrial pathologies associated with postmenopausal tamoxifen treatment. Gynecologic Oncology 2004;94(2):256-66

\section{Davies 2013}

Davies C, Pan H, Godwin J, Gray R, Arriagada R, et al for the Adjuvant Tamoxifen: Longer Against Shorter (ATLAS)
Collaborative Group. Long-term effects of continuing adjuvant tamoxifen to 10 years versus stopping at 5 years after diagnosis of oestrogen receptor-positive breast cancer: ATLAS, a randomised trial. Lancet 2013;381(9869):805-816.

\section{EBCTCG 2005}

Early Breast Cancer Trialists Collaborative Group (EBCTCG). Effects of chemotherapy and hormonal therapy for early breast cancer on recurrence and 15-year survival: an overview of the randomised trials. Lancet 2005;365(9472):1687-717.

\section{Higgins 2011}

Higgins JPT, Green S (editors). Cochrane Handbook for Systematic Reviews of Interventions Version 5.1.0 [updated March 2011]. The Cochrane Collaboration, 2011. Available from www.cochrane-handbook.org.

\section{Kedar 1994}

Kedar RP, Bourne TH, Powles TJ, Collins WP, Ashley SE, Cosgrove DO, et al. Effects of tamoxifen on uterus and ovaries of postmenopausal women in a randomized breast cancer prevention trial. Lancet 1994;343:1318-21.

\section{Lyytinen 2009}

Lyytinen HK, Dyba T, Ylikorkala O, Pukkala El. A cases control study on hormone therapy as a risk factor for breast cancer in Finland. International Journal of Cancer July 2009;126(2):483-9.

\section{Scommegna 1970}

Scommegna A, Pandya GN, Christ M, Lee AW, Cohen MR. Intrauterine administration of progesterone by a slow releasing device. Fertility and Sterility 1970;21(3):201-10.

\section{Trinh 2008}

Trinh XB, Tjalma WA, Makar AP, Buytaert G, Weyler J, van Dam $\mathrm{Pa}$. Use of the levonorgestrel-releasing intrauterine system in breast cancer patients. Fertility and Sterility 2008;90(1):17-22.

\section{Van Leeuwen 1994}

Van Leeuwen FE, Benraadt J, Coesbergh JW, Kiemeney LA, Gimbrere $\mathrm{CH}$, Otter R. Risk of endometrial cancer after tamoxifen treatment of breast cancer. Lancet 1994;343:1318-21.

\section{www.cancer.org}

American Cancer Society. www.cancer.org. www.cancer.org 2008.

\section{Xiao 1990}

Xiao BL, Zhou LY, Zhang XL, Jia MC, Luukkainen T, Allonen H. Pharmacokinetic and pharmacodynamic studies of levonorgestrel-releasing intrauterine device. Contraception 1990;41(4):353-62.

* Indicates the major publication for the study 


\section{CHARACTERISTICS OF STUDIES}

\section{Characteristics of included studies [ordered by study ID]}

\section{Chan 2007}

\begin{tabular}{ll}
\hline Methods & Randomised controlled trial \\
\hline Participants & $\begin{array}{l}\text { Pre- and postmenopausal women who required adjuvant tamoxifen for breast cancer after completion } \\
\text { of postoperative radiotherapy and chemotherapy. }\end{array}$ \\
129 women randomised. \\
Exclusion criteria included contraindication for intrauterine device, such as pelvic inflammatory dis- \\
ease, congenital uterine anomaly or uterine cavity length $>10 \mathrm{~cm}$.
\end{tabular}

Notes Study funding: The Chinese University of Hong Kong Department of Obstetrics and Gynaecology

\section{Risk of bias}

\begin{tabular}{lll}
\hline Bias & Authors' judgement & Support for judgement \\
\hline $\begin{array}{l}\text { Random sequence genera- } \\
\text { tion (selection bias) }\end{array}$ & Low risk & Computer generated random number series. \\
\hline
\end{tabular}

Allocation concealment $\quad$ Low risk $\quad$ Allocation in serially numbered sealed envelopes.
(selection bias)

\begin{tabular}{ll}
\hline $\begin{array}{l}\text { Blinding (performance } \\
\text { bias and detection bias) }\end{array}$ & Low risk \\
$\begin{array}{l}\text { All outcomes } \\
\end{array}$ & $\begin{array}{l}\text { The pathologist was blinded to the randomisation. Even though the provider } \\
\text { and participant were not blinded given the clinical intervention (insertion of } \\
\text { the LNG-IUS), the blinding of providers and participants is considered very un- } \\
\text { likely to influence the outcomes. }\end{array}$ \\
\hline
\end{tabular}

\begin{tabular}{|c|c|c|}
\hline $\begin{array}{l}\text { Incomplete outcome data } \\
\text { (attrition bias) } \\
\text { All outcomes }\end{array}$ & Unclear risk & $\begin{array}{l}\text { At } 12 \text { months of follow-up, } 16 / 129 \text { (12\%) participants ( } 7 \text { in the control group } \\
\text { and } 9 \text { in the treatment group) were lost to follow up or dropped out. } 113 \\
\text { women ( } 58 \text { in the control and } 55 \text { in the treatment group) were analysed. }\end{array}$ \\
\hline
\end{tabular}

At 60 months of follow up, 35/129 (27\%) participants (17 in the control group and 18 in the treatment group) were lost to follow up. 94 women (48 in the control and 46 in the treatment group) were analysed. 
Chan 2007 (Continued)

There is no description of the population who dropped out or comparison of drop-outs to participants who remained in the study; as such this is judged as unclear risk of bias.

\begin{tabular}{lll}
\hline $\begin{array}{l}\text { Selective reporting (re- } \\
\text { porting bias) }\end{array}$ & Low risk & All outcomes were reported as planned. \\
\hline Other bias & Low risk & No additional biases to report. \\
\hline
\end{tabular}

Gardner 2000

\begin{tabular}{ll}
\hline Methods & Randomised controlled trial \\
\hline Participants & $\begin{array}{l}\text { Postmenopausal women who had been on adjuvant tamoxifen for at least } 12 \text { months. Postmenopause } \\
\text { was defined by serum estradiol < } 50 \mathrm{pmol} / \mathrm{L} .\end{array}$ \\
122 women randomised; 9 were excluded after randomization (6 were premenopausal, 3 with unsatis- \\
factory hysteroscopy). \\
Additional exclusion criteria included suspected pelvic inflammatory disease, active liver disease, his- \\
tory of malignant disease other than breast cancer, grade 3 submucous fibroid, endometrial polyps, \\
and refusal to receive the levonorgestrel intrauterine system.
\end{tabular}

Interventions

Two interventions compared:

1. Endometrial surveillance alone (transvaginal ultrasound at base, 6 months, 12 months, 24 months, 36 months, and 48 months; hysteroscopy at base, 12 months, 24 months, 36 months, and 48 months; endometrial sampling at base, 12 months, 24 months, 36 months, and 48 months)

2. Endometrial surveillance with insertion of the levonorgestrel intrauterine system

1. Development of endometrial polyps at 12 months (52 in control group and 47 in treatment group)
and at final study visit ranging from 24 months ( 29 in control group and 31 in treatment group) to 48
months ( 9 in control group and 6 in treatment group)
2. Endometrial hyperplasia at final study visit ( 24 to 48 months)
3. Endometrial cancer at final study visit ( 24 to 48 months)
4. Submucosal fibroids at 12 months
5. Breast cancer recurrence at final study visit ( 24 to 48 months)
6. Breast cancer-related death at final study visit ( 24 to 48 months)

Notes

Study funding: A grant from Trent NHS Research and Development, with support from The University of Leicester and The University Hospitals of Leicester NHS Trust

\section{Risk of bias}

\begin{tabular}{lll}
\hline Bias & Authors' judgement & Support for judgement \\
\hline $\begin{array}{l}\text { Random sequence genera- } \\
\text { tion (selection bias) }\end{array}$ & Unclear risk & No information provided on random sequence generation. \\
\hline $\begin{array}{l}\text { Allocation concealment } \\
\text { (selection bias) }\end{array}$ & Low risk & Pre-prepared serially-numbered sealed envelopes. \\
\hline $\begin{array}{l}\text { Blinding (performance } \\
\text { bias and detection bias) } \\
\text { All outcomes }\end{array}$ & Low risk & $\begin{array}{l}\text { The pathologist was blinded to the randomization. Even though the provider } \\
\text { and participant were not blinded given the clinical intervention (insertion of } \\
\text { the LNG-IUS), the blinding of providers and participants is considered very un- } \\
\text { likely to influence the outcomes. }\end{array}$ \\
\hline
\end{tabular}


Gardner 2000 (Continued)

Incomplete outcome data Unclear risk At 12 months of follow-up, 23/122 (19\%) of participants (6 in control group and (attrition bias)

17 in treatment group) were lost to follow-up or dropped out. 99 women (52 in

All outcomes control and 47 in treatment) were included in the analyses. There were no evidence of differences in baseline data between women who completed and did not complete the study. These data are at low risk of attrition bias.

The 24, 36 and 48 months follow up data are considered at high risk of attrition bias. At 24 months of follow-up, 62/122 (51\%) of participants were not included in the analyses as they were lost to follow-up or dropped out. At 36 months of follow-up, 83/122 (68\%) of participants were lost to follow-up or dropped out. At 48 months of follow-up, only 15 women were included in the analyses, due to $107 / 122(88 \%)$ of participants lost to follow-up or dropped out.

Selective reporting (re- Low risk $\quad$ All outcomes were reported as planned.
porting bias)
porting bias)

\begin{tabular}{ll}
\hline Other bias $\quad$ Low risk No additional bias to report. \\
\hline
\end{tabular}

Kesim 2008

\begin{tabular}{|c|c|}
\hline Methods & Randomised controlled trial \\
\hline \multirow[t]{3}{*}{ Participants } & Postmenopausal women who had been on adjuvant tamoxifen for more than 12 months. \\
\hline & $\begin{array}{l}148 \text { women randomised; } 6 \text { were excluded after randomisation ( } 2 \text { refused LNG-IUS, and } 4 \text { in whom the } \\
\text { LNG-IUS could not be fitted). }\end{array}$ \\
\hline & $\begin{array}{l}\text { Exclusion criteria included contraindication for intrauterine device (such as pelvic inflammatory dis- } \\
\text { ease), progestogen treatment since diagnosis of breast cancer, history of malignant disease other than } \\
\text { breast cancer, allergy to polyethylene, and refusal to receive the levonorgestrel intrauterine system. }\end{array}$ \\
\hline \multirow[t]{3}{*}{ Interventions } & Two interventions compared: \\
\hline & $\begin{array}{l}\text { 1. Endometrial surveillance alone (transvaginal ultrasound, hysteroscopy, and endometrial sampling at } \\
\text { base and } 36 \text { months) }\end{array}$ \\
\hline & 2. Endometrial surveillance with insertion of the levonorgestrel intrauterine system \\
\hline \multirow[t]{3}{*}{ Outcomes } & 1. Development of endometrial polyps at 36 months \\
\hline & 2. Endometrial hyperplasia at 36 months \\
\hline & 3. Abnormal vaginal bleeding or spotting at 5 and 12 months \\
\hline
\end{tabular}

Notes Study funding: not reported.

\section{Risk of bias}

Bias Authors' judgement Support for judgement

Random sequence genera- Low risk Allocation by computer-aided numbering of sealed envelopes. tion (selection bias)

\begin{tabular}{lll}
\hline $\begin{array}{l}\text { Allocation concealment } \\
\text { (selection bias) }\end{array}$ & Low risk & Pre-prepared numbered sealed envelopes. \\
\hline $\begin{array}{l}\text { Blinding (performance } \\
\text { bias and detection bias) } \\
\text { All outcomes }\end{array}$ & Low risk & $\begin{array}{l}\text { The pathologist was blinded to the randomization. Even though the provider } \\
\text { and participant were not blinded given the clinical intervention (insertion of }\end{array}$
\end{tabular}


Incomplete outcome data Low risk (attrition bias)

All outcomes
After randomization, 6/148 (4\%) of women were excluded (2 refused LNG-IUS, and 4 in whom the LNG-IUS could not be fitted).

At 36 months of follow-up, 0 participants were lost to follow-up or dropped out. 142 women were included in the analyses. These data are at low risk of attrition bias.

Selective reporting (re- Low risk All outcomes were reported as planned.
porting bias)

All outcomes were reported as planned.

Other bias Low risk No additional bias to report.

Omar 2010

\begin{tabular}{|c|c|}
\hline Methods & Randomised controlled trial \\
\hline \multirow[t]{3}{*}{ Participants } & $\begin{array}{l}\text { Pre- and postmenopausal women with early stage breast cancer who required adjuvant tamoxifen after } \\
\text { completion of postoperative radiation and chemotherapy. }\end{array}$ \\
\hline & $\begin{array}{l}150 \text { women randomised; } 18 \text { were excluded after randomization ( } 8 \text { from the control and } 10 \text { from the } \\
\text { treatment group declined participation). At baseline, } 9 \text { women ( } 4 \text { from control and } 5 \text { from treatment) } \\
\text { were excluded due to an unsuccessful hysteroscopy. }\end{array}$ \\
\hline & $\begin{array}{l}\text { Exclusion criteria included age }>60 \text { years, contraindications for intrauterine device (such as pelvic in- } \\
\text { flammatory disease, uterine cavity }>8 \mathrm{~cm} \text { ), active liver disease, history of progestogen treatment since } \\
\text { diagnosis of breast cancer, history of malignant disease other than breast cancer, allergy to polyethyl- } \\
\text { ene, and refusal to receive the levonorgestrel intrauterine system. }\end{array}$ \\
\hline
\end{tabular}

\section{Interventions}

Two interventions compared:
1. Endometrial surveillance alone (transvaginal ultrasound at base, 12 and 24 months; hysteroscopy and endometrial sampling at base and 24 months)

2. Endometrial surveillance with insertion of the levonorgestrel intrauterine system

\begin{tabular}{ll}
\hline Outcomes & 1. Development of endometrial polyps at 24 months \\
2. Endometrial hyperplasia at 24 months \\
3. Submucosal fibroids at 24 months \\
4. Abnormal vaginal bleeding or spotting at 12 months and 24 months \\
5. Breast cancer-related death at 12 months \\
\hline Notes & Study funding: not reported. \\
\hline
\end{tabular}

\section{Risk of bias}

\begin{tabular}{lll}
\hline Bias & Authors' judgement & Support for judgement \\
\hline $\begin{array}{l}\text { Random sequence genera- } \\
\text { tion (selection bias) }\end{array}$ & Low risk & Allocation by computer-generated random number series. \\
\hline $\begin{array}{l}\text { Allocation concealment } \\
\text { (selection bias) }\end{array}$ & Low risk & Pre-prepared serially-numbered sealed envelopes. \\
\hline $\begin{array}{l}\text { Blinding (performance } \\
\text { bias and detection bias) }\end{array}$ & Low risk & $\begin{array}{l}\text { The pathologist was blinded to the randomization. Even though the provider } \\
\text { and participant were not blinded given the clinical intervention (insertion of }\end{array}$ \\
\hline
\end{tabular}

Levonorgestrel intrauterine system for endometrial protection in women with breast cancer on adjuvant tamoxifen (Review) 
Omar 2010 (Continued)

All outcomes the LNG-IUS), the blinding of providers and participants is considered very unlikely to influence the outcomes.
Incomplete outcome data Low risk (attrition bias)

All outcomes
After randomization, $18 / 150$ (12\%) of women were excluded (8 from the control and 10 from the treatment group declined participation). At baseline, $9 / 150(6 \%)$ of women ( 4 from control and 5 from treatment) were excluded due to an unsuccessful hysteroscopy.

At 12 months of follow-up, 2/123 (2\%) of participants [ 1 in control group (breast cancer-related death) and 1 in treatment group (hysterectomy)] were lost to follow up. At 24 months of follow-up (62 in the control group and 59 in the treatment group), 0 participants were lost to follow up. At both follow-up time points, 121 women were included in the analyses. There were no evidence of differences in baseline data between women who completed and did not complete the study. These data are at low risk of attrition bias.

Selective reporting (re- Low risk All outcomes were reported as planned.
porting bias)

Other bias Low risk No additional bias to report.

DATA AND ANALYSES

\section{Comparison 1. LNG-IUS with endometrial surveillance versus endometrial surveillance alone}

\begin{tabular}{|c|c|c|c|c|}
\hline Outcome or subgroup title & $\begin{array}{l}\text { No. of } \\
\text { studies }\end{array}$ & $\begin{array}{l}\text { No. of } \\
\text { partici- } \\
\text { pants }\end{array}$ & Statistical method & Effect size \\
\hline 1 Endometrial Polyps & 4 & & Peto Odds Ratio (Peto, Fixed, $95 \% \mathrm{Cl}$ ) & Subtotals only \\
\hline $\begin{array}{l}1.1 \text { Short term follow-up ( } 12 \\
\text { months) }\end{array}$ & 2 & 212 & Peto Odds Ratio (Peto, Fixed, 95\% Cl) & $0.22[0.08,0.64]$ \\
\hline $\begin{array}{l}1.2 \text { Long term follow-up ( } 24 \text { to } 60 \\
\text { months) }\end{array}$ & 4 & 417 & Peto Odds Ratio (Peto, Fixed, 95\% Cl) & $0.22[0.13,0.39]$ \\
\hline 2 Endometrial Hyperplasia & 4 & 417 & Peto Odds Ratio (Peto, Fixed, 95\% Cl) & $0.13[0.03,0.67]$ \\
\hline 3 Endometrial Cancer & 2 & 154 & Peto Odds Ratio (Peto, Fixed, 95\% Cl) & $0.0[0.0,0.0]$ \\
\hline 4 Fibroids & 3 & 314 & Peto Odds Ratio (Peto, Fixed, 95\% Cl) & $0.48[0.16,1.46]$ \\
\hline $\begin{array}{l}5 \text { Abnormal Vaginal Bleeding or } \\
\text { Spotting }\end{array}$ & 3 & & Peto Odds Ratio (Peto, Fixed, 95\% Cl) & Subtotals only \\
\hline 5.112 months & 3 & 376 & Peto Odds Ratio (Peto, Fixed, 95\% Cl) & $7.26[3.37,15.66]$ \\
\hline 5.224 months & 2 & 233 & Peto Odds Ratio (Peto, Fixed, $95 \% \mathrm{Cl}$ ) & $2.72[1.04,7.10]$ \\
\hline 5.345 months & 1 & 100 & Peto Odds Ratio (Peto, Fixed, $95 \% \mathrm{Cl}$ ) & $0.0[0.0,0.0]$ \\
\hline 5.460 months & 1 & 94 & Peto Odds Ratio (Peto, Fixed, 95\% Cl) & $0.0[0.0,0.0]$ \\
\hline
\end{tabular}




\begin{tabular}{llllll}
\hline Outcome or subgroup title & $\begin{array}{l}\text { No. of } \\
\text { studies }\end{array}$ & $\begin{array}{l}\text { No. of } \\
\text { partici- } \\
\text { pants }\end{array}$ & Statistical method & Effect size \\
\hline 6 Breast Cancer Recurrence & 2 & 154 & Peto Odds Ratio (Peto, Fixed, 95\% Cl) & $1.74[0.64,4.74]$ \\
\hline 7 Breast Cancer-related Death & 3 & 277 & Peto Odds Ratio (Peto, Fixed, 95\% Cl) & $1.02[0.36,2.84]$ \\
\hline
\end{tabular}

Analysis 1.1. Comparison 1 LNG-IUS with endometrial surveillance versus endometrial surveillance alone, Outcome 1 Endometrial Polyps.

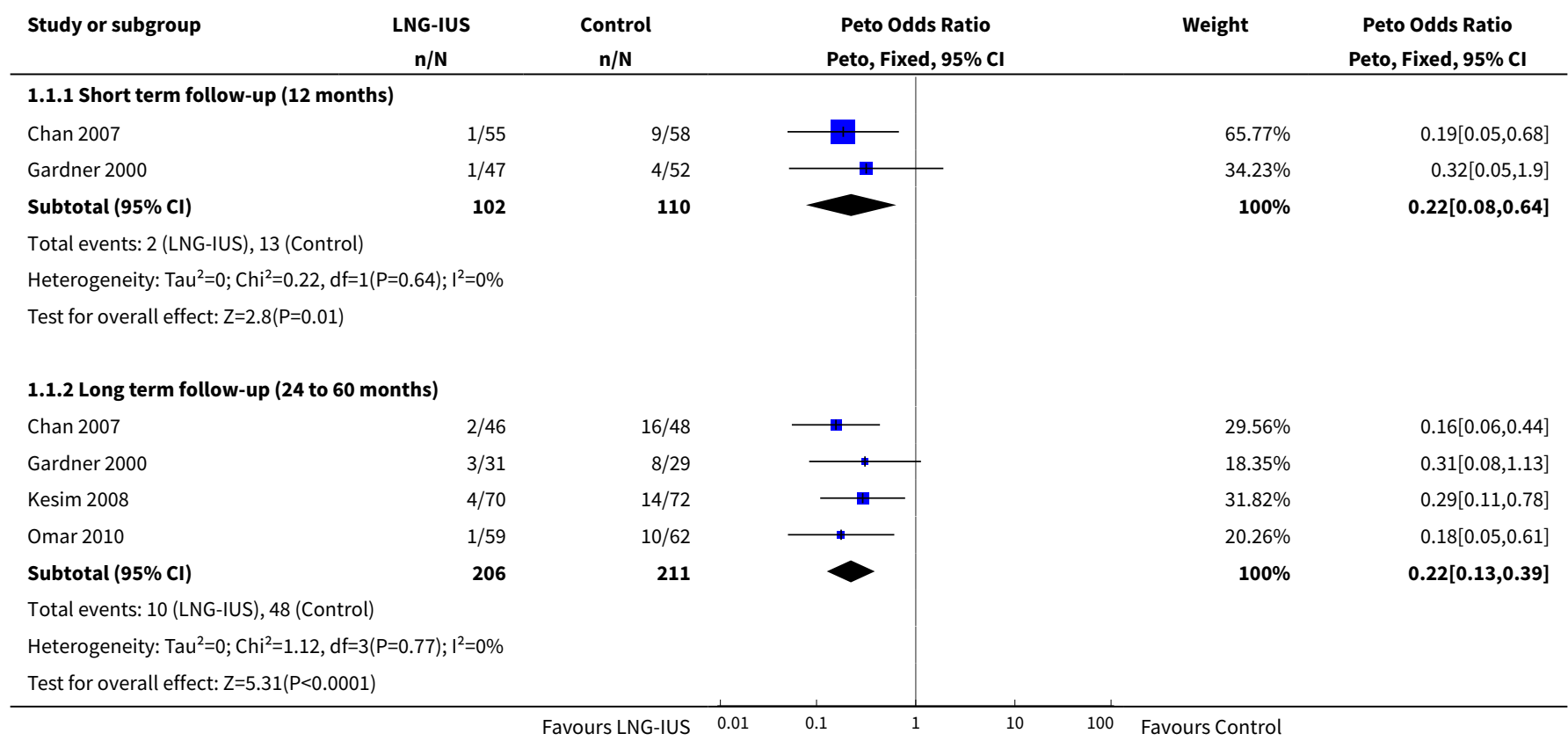

Analysis 1.2. Comparison 1 LNG-IUS with endometrial surveillance versus endometrial surveillance alone, Outcome 2 Endometrial Hyperplasia.

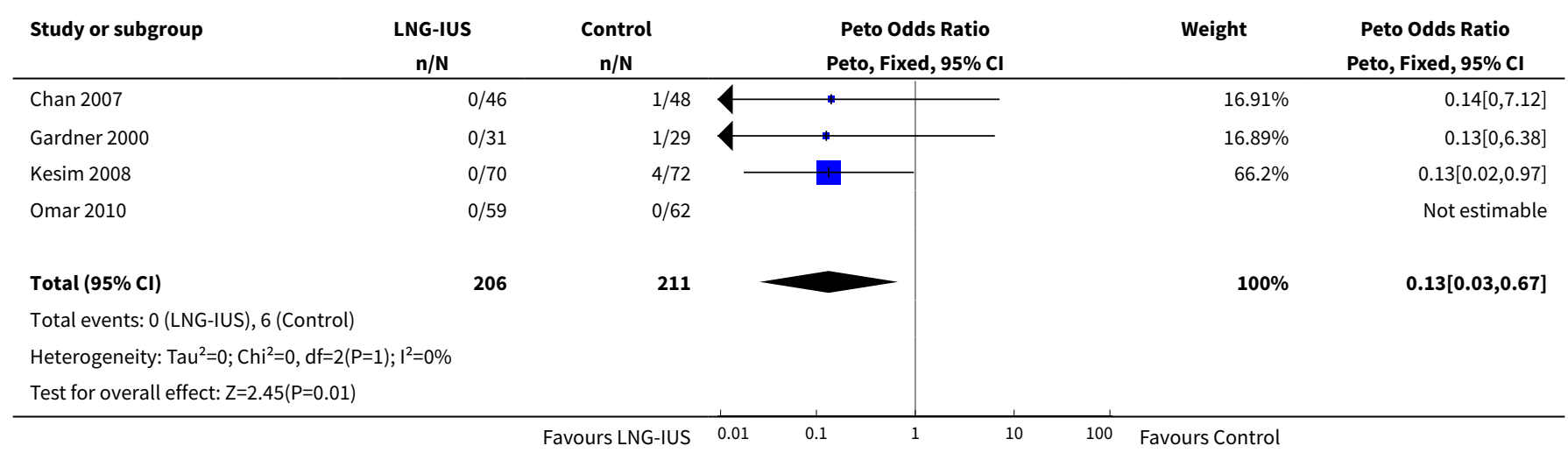


Analysis 1.3. Comparison 1 LNG-IUS with endometrial surveillance versus endometrial surveillance alone, Outcome 3 Endometrial Cancer.

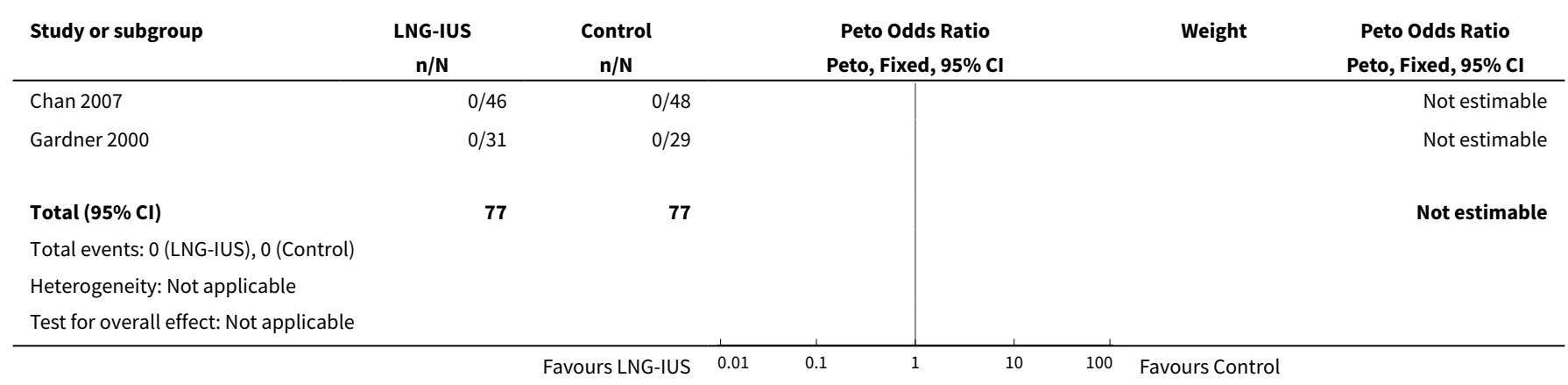

Analysis 1.4. Comparison 1 LNG-IUS with endometrial surveillance versus endometrial surveillance alone, Outcome 4 Fibroids.

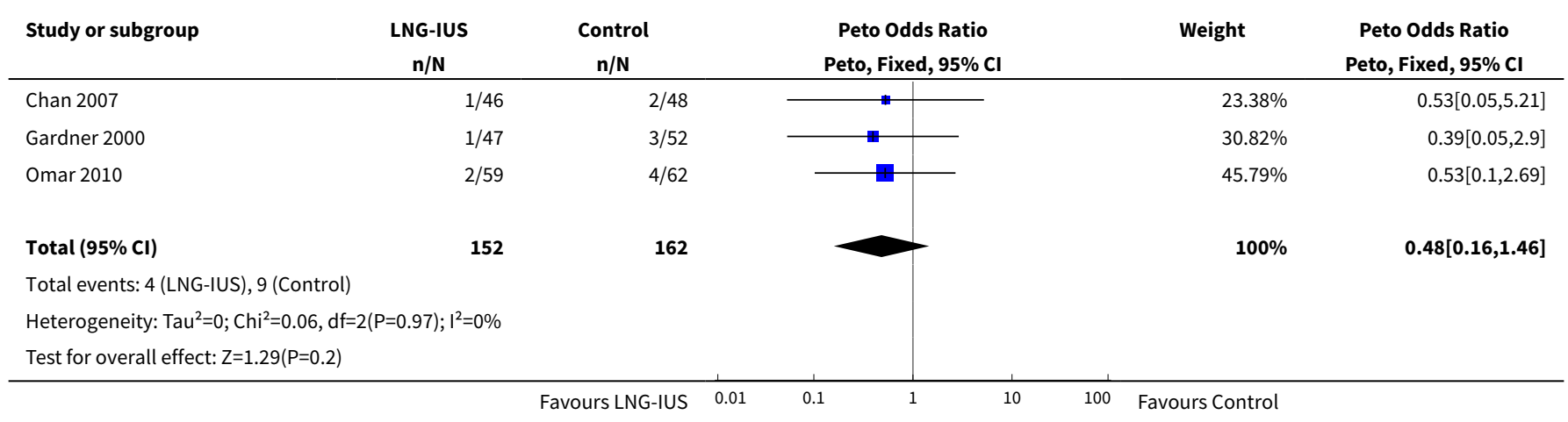

Analysis 1.5. Comparison 1 LNG-IUS with endometrial surveillance versus endometrial surveillance alone, Outcome 5 Abnormal Vaginal Bleeding or Spotting.

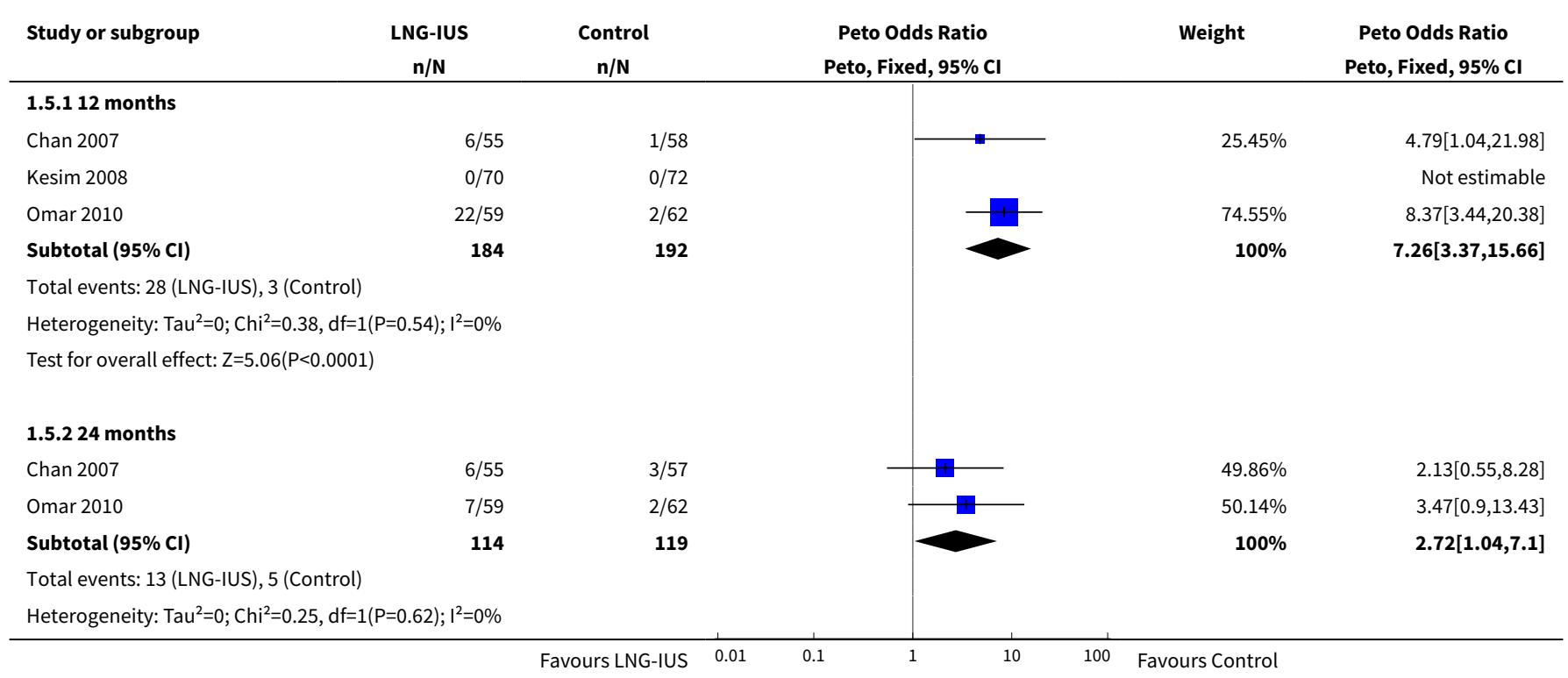




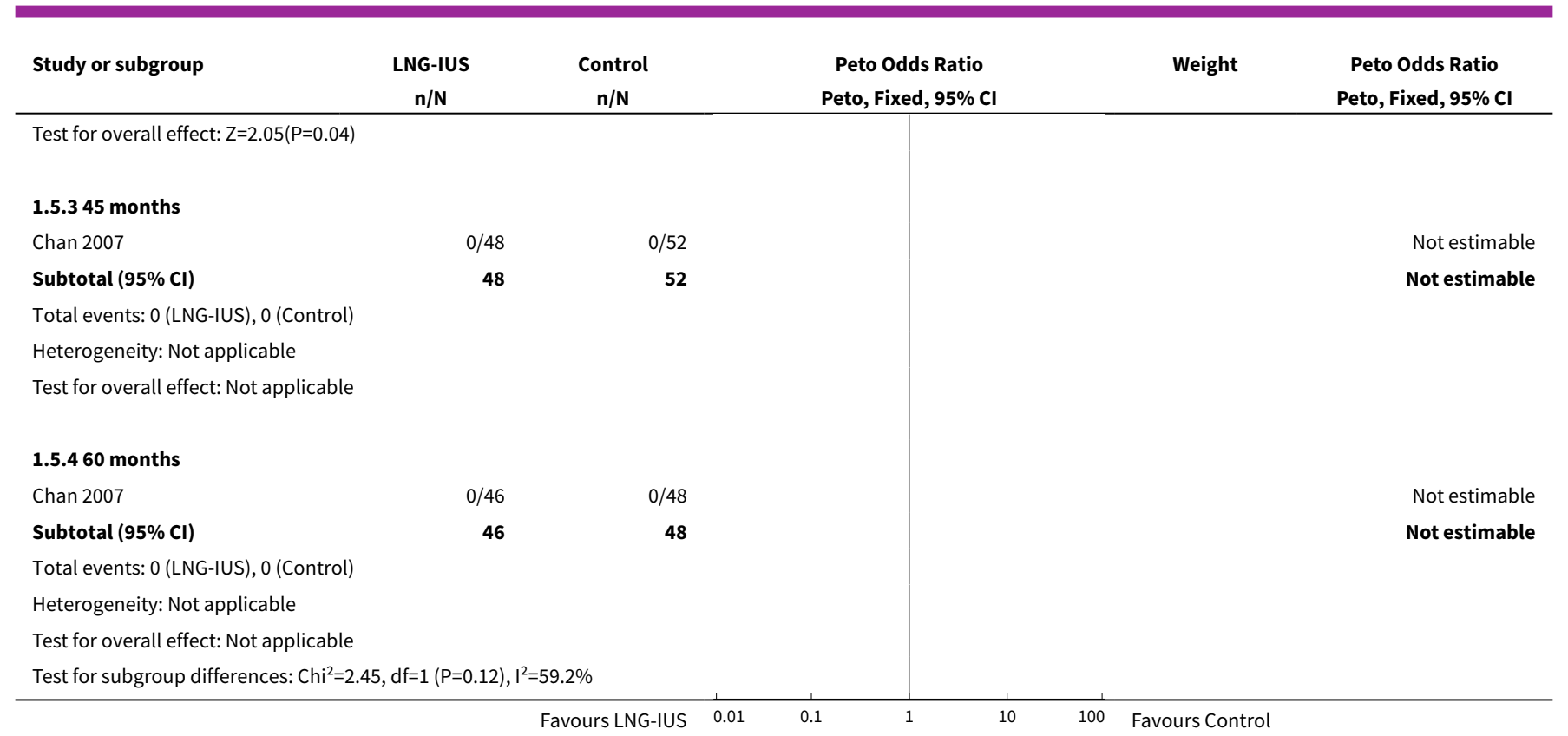

Analysis 1.6. Comparison 1 LNG-IUS with endometrial surveillance versus endometrial surveillance alone, Outcome 6 Breast Cancer Recurrence.

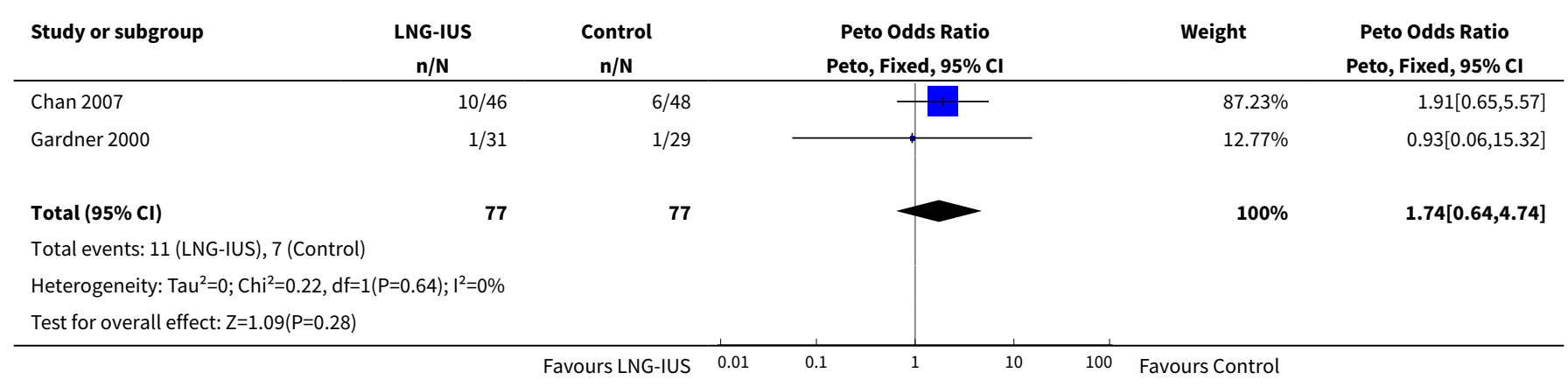

Analysis 1.7. Comparison 1 LNG-IUS with endometrial surveillance versus endometrial surveillance alone, Outcome 7 Breast Cancer-related Death.

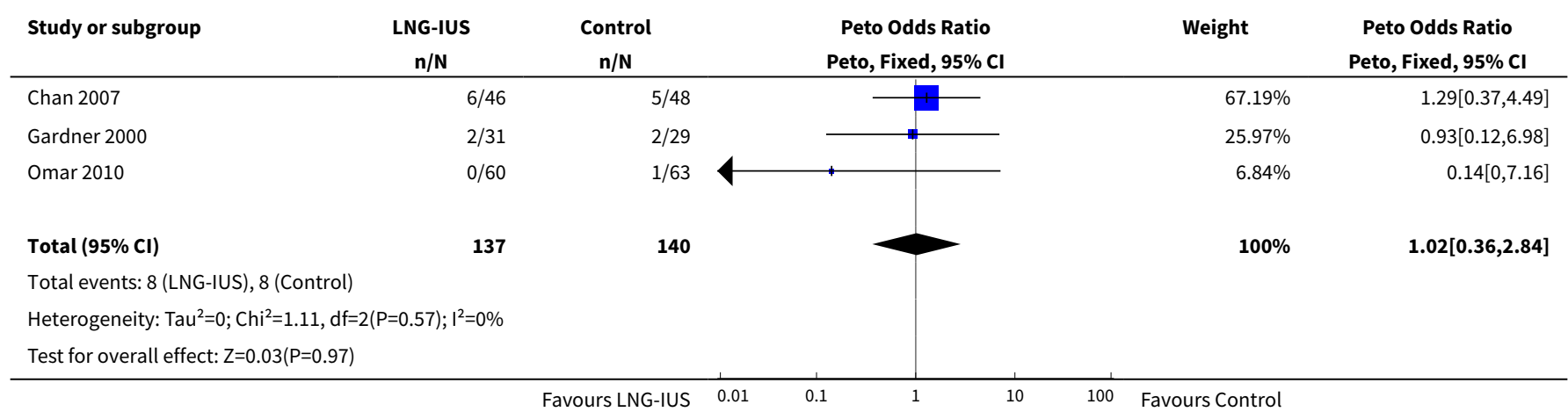




\section{ADDITIONALTABLES}

Table 1. Chan 2007 \& Wong 2013

\begin{tabular}{|c|c|c|c|}
\hline & $\begin{array}{l}\text { Treatment } \\
\text { Group }\end{array}$ & Control & $P$ value \\
\hline \multicolumn{4}{|l|}{6 months follow-up } \\
\hline Randomised & 64 & 65 & \\
\hline Completed & 55 & 58 & \\
\hline Abnormal vaginal bleeding or spotting & 20 & 1 & $<0.001$ \\
\hline \multicolumn{4}{|l|}{12 months follow-up } \\
\hline Completed & 55 & 58 & \\
\hline Abnormal vaginal bleeding or spotting & 6 & 1 & 0.06 \\
\hline Endometrial polyps & 1 & 9 & 0.02 \\
\hline Endometrial hyperplasia & 0 & 0 & \\
\hline Fibroids & 1 & 2 & 1.0 \\
\hline
\end{tabular}

\section{4 months follow-up}

\begin{tabular}{llll}
\hline Completed & 55 & 57 & \\
\hline & & & \\
\hline Abnormal vaginal bleeding or spotting & 6 & 3 & 0.45
\end{tabular}

\section{5 months follow-up}

\begin{tabular}{lll}
\hline Completed & 48 & 52 \\
\hline
\end{tabular}

\section{0 months follow-up}


Table 1. Chan 2007 \& Wong 2013 (Continued)

Completed

\begin{tabular}{|c|c|c|c|}
\hline Abnormal vaginal bleeding or spotting & 0 & 0 & \\
\hline Endometrial polyps & 2 & 16 & $<0.001$ \\
\hline Endometrial hyperplasia & 0 & 1 & 1.0 \\
\hline Endometrial cancer & 0 & 0 & \\
\hline Fibroids & 1 & 2 & 1.0 \\
\hline Breast cancer recurrence & 10 & 6 & 0.25 \\
\hline Breast cancer-related deaths & 6 & 5 & 0.71 \\
\hline
\end{tabular}

Table 2. Gardner 2000 \& 2009

\begin{tabular}{|c|c|c|c|}
\hline & $\begin{array}{l}\text { Treatment } \\
\text { Group }\end{array}$ & Control & $P$ value \\
\hline \multicolumn{4}{|l|}{12 months follow-up } \\
\hline Randomised & 64 & 58 & \\
\hline Completed & 47 & 52 & \\
\hline Endometrial polyps & 1 & 4 & 0.4 \\
\hline Endometrial hyperplasia & 0 & 1 & \\
\hline Fibroids & 1 & 3 & 0.2 \\
\hline
\end{tabular}

\section{Final follow-up $(24,36$, or 48 months)}

\begin{tabular}{lcc}
\hline Completed at 24 months & 31 & 29 \\
\hline Completed at 36 months & 19 & 20 \\
\hline Completed at 48 months & 6 & 9 \\
\hline
\end{tabular}

\begin{tabular}{llc}
\hline Endometrial polyps & 3 & 8 \\
\hline Endometrial hyperplasia & 0 & 1 \\
\hline Endometrial cancer & 0 & 0 \\
\hline \hline
\end{tabular}


Table 2. Gardner 2000 \& 2009 (Continued)

\begin{tabular}{lcc} 
Breast cancer recurrence & 1 & 1 \\
\hline Breast cancer-related deaths & 2 & 2 \\
\hline
\end{tabular}

Table 3. Kesim 2008

Treatment Control P value
Group

Group

\section{5 months follow-up}

\begin{tabular}{lll}
\hline Randomised & 70 & 72 \\
\hline Completed & 70 & 72 \\
\hline & & \\
\hline Abnormal vaginal bleeding or spotting & 7 & 0 \\
\hline
\end{tabular}

\section{2 months follow-up}

\begin{tabular}{lll}
\hline Randomised & 70 & 72 \\
\hline Completed & 70 & 72 \\
\hline
\end{tabular}

0

\section{6 months follow-up}

\begin{tabular}{llll}
\hline Randomised & 70 & 72 & 72 \\
\hline Completed & 70 & & \\
\hline & & & \\
\hline Endometrial polyps & 4 & 14 & $<0.05$ \\
\hline Endometrial hyperplasia & 0 & 4 & $<0.05$ \\
\hline
\end{tabular}

Table 4. Omar 2010

Treatment Control P value
Group

\section{2 months follow-up}


Table 4. Omar 2010 (Continued)

\begin{tabular}{llll} 
Randomised & 75 & 75 & 63 \\
\hline Completed & 60 & & \\
\hline & & 22 & $<0.001$ \\
\hline Abnormal vaginal bleeding or spotting & 22 & 1 & 0 \\
\hline Breast cancer-related deaths & 0 & 2 \\
\hline
\end{tabular}

\section{4 months follow-up}

$\begin{array}{lrr}\text { Completed } & 59 & 62\end{array}$

\begin{tabular}{|c|c|c|c|}
\hline Abnormal vaginal bleeding or spotting & 7 & 2 & 0.08 \\
\hline Endometrial polyps & 1 & 10 & 0.02 \\
\hline Endometrial hyperplasia & 0 & 0 & \\
\hline Fibroids & 2 & 4 & 1.0 \\
\hline
\end{tabular}

\section{AP P E N DICES}

\section{Appendix 1. MDSG search (October 2015)}

Keywords CONTAINS "IUD" or "levonorgestrel intrauterine system" or "levonorgestrel-releasing intrauterine device" or "levonorgestrelreleasing intrauterine system" or "Levonorgestrel-Therapeutic-Use" or "LNG-IUS" or "LNG20"or "Intrauterine Releasing Devices" or "Intrauterine Devices Medicated" or "intrauterine devices" or "intrauterine device" or "intrauterine contraceptive devices" or "Mirena" or Title CONTAINS "IUD" or "levonorgestrel intrauterine system" or "levonorgestrel-releasing intrauterine device" or "levonorgestrelreleasing intrauterine system" or "Levonorgestrel-Therapeutic-Use" or "LNG-IUS" or "LNG20"or "Intrauterine Releasing Devices" or "Intrauterine Devices Medicated" or "intrauterine devices" or "intrauterine device" or "intrauterine contraceptive devices" or "Mirena"

AND

Keywords CONTAINS "breast cancer" or "breast cancer incidence"or "breast changes"or "breast disease"or "breast outcomes"or "cancer risk"or "endometrial cancer"or "endometrial hyperplasia"or"endometrial pathology"or"endometrial polyps"or"endometrial proliferation"or "polyps" or Title CONTAINS "breast cancer" or "breast cancer incidence"or "breast changes"or "breast disease"or "breast outcomes"or "cancer risk"or "endometrial cancer"or "endometrial hyperplasia"or"endometrial pathology"or"endometrial polyps"or"endometrial proliferation"or "polyps"

\section{Appendix 2. CBCG search (October 2015)}

Details regarding the search strategies used by the Cochrane Breast Cancer Group for the identification of studies and procedures used to code references for the Specialised Register are outlined in the Group's module: www.onlinelibrary.wiley.com/o/cochrane/clabout/ articles/BREASTCA/frame.html

The following key words were used to identify relevant studies for consideration: "IUD", "intrauterine devices", "intrauterine system", "levonorgestrel intrauterine system", "levonorgestrel-releasing intrauterine device", "levonorgestrel-releasing intrauterine system", "levonorgestrel-therapeutic use", "LNG-IUS", "LNG20" and "Mirena". 


\section{Appendix 3. CENTRAL search (October 2015)}

1 exp Breast Neoplasms/ (7208)

2 Breast Neoplasms, Male/ (23)

31 not $2(7185)$

4 (Breast cancer\$ or Breast Neoplasm\$).tw. (15233)

53 or $4(16346)$

6 exp Intrauterine Devices, Medicated/ (300)

7 Intrauterine Device\$.tw. (350)

8 (LNG IUS or LNG IUD).tw. (133)

9 Levonorgestrel-releasing intrauterine system $\$ . t w . ~(106)$

10 Levonorgestrel-releasing intrauterine device\$.tw. (43)

11 (IUD\$ or Mirena).tw. (550)

12 or/6-11 (784)

13 Intrauterine Devices, Medicated/ae [Adverse Effects] (1)

14 exp Neoplasm Recurrence, Local/ (2984)

15 exp Endometrial Hyperplasia/ (94)

16 exp Endometrial Neoplasms/ (274)

17 exp Adenocarcinoma/ (3971)

18 exp Neoplasm Metastasis/ (3273)

19 exp Antineoplastic Agents, Hormonal/ae [Adverse Effects] (346)

20 exp Tamoxifen/ae [Adverse Effects] (74)

21 breast cancer recurrence\$.tw. (150)

22 recurrent breast cancer.tw. (119)

23 Local Neoplasm Recurrence\$.tw. (0)

24 secondary breast cancer\$.tw. (24)

25 secondary neoplasm\$.tw. (11)

26 secondary cancer\$.tw. (30)

27 Neoplasm Metastasis.tw. (2)

28 cancer metastasis.tw. (35)

29 advanced breast cancer.tw. (1815)

30 breast cancer survival.tw. (57)

31 Endometrial Hyperplasia.tw. (192)

32 Endometri\$ patholog\$.tw. (44)

33 Endometri\$ polyp\$.tw. (86)

34 Endometrial adenocarcinoma\$.tw. (30) 
35 endometrial cancer.tw. (458)

36 or/13-35 (11723)

375 and 12 and 36 (6)

\section{Appendix 4. The Cochrane Library (October 2015)}

\#1 "Clinical Trial" or "Phase I Clinical Trial" or "Phase II Clinical Trial" or "Phase III Clinical Trial" or "Phase IV Clinical Trial" or "Controlled Clinical Trial" or "Multicenter Study" or "Randomized Controlled Trial" or "Pragmatic Clinical Trial" in Cochrane Reviews (Reviews and Protocols) and Trials

\#2 mh "Breast Neoplasms" not mh "Breast Neoplasms, Male" or "Breast cancer" or "Breast Neoplasms"

\#3 mh "Intrauterine Devices" or mh "Levonorgestrel" or "Intrauterine Devices" or "IUD" or "Medicated Intrauterine Devices" or "LNG IUS" or "Levonorgestrel-releasing intrauterine system" or "Mirena" or "Levonorgestrel"

\#4 mh "Intrauterine Devices/adverse effects" or mh "Levonorgestrel/adverse effects" or mh "Neoplasm Recurrence, Local" or mh "Breast Neoplasms/secondary" or mh "Neoplasms/secondary" or mh "Endometrial Hyperplasia" or mh "Neoplasm Metastasis" or "breast cancer recurrence" or "recurrent breast cancer" or "Local Neoplasm Recurrence" or "secondary breast cancer" or "secondary neoplasms" or "secondary cancers" or "Neoplasm Metastasis" or "cancer metastasis" or "breast cancer metastasis" or "advanced breast cancer" or "breast cancer survival" or "Endometrial Hyperplasia" or "Endometrial pathology" or "Endometrial polyps" or "Endometrial adenocarcinoma" or "endometrial cancer"

$\# 5 \# 1$ and \#2 and \#3 and \#4

\section{Appendix 5. MEDLINE search (1946 to October 2015)}

1 exp Breast Neoplasms/ (239438)

2 Breast Neoplasms, Male/ (2450)

31 not 2 (236988)

4 (Breast cancer\$ or Breast Neoplasm\$).tw. (200308)

53 or $4(285644)$

6 exp Intrauterine Devices, Medicated/ (2884)

7 Intrauterine Device\$.tw. (4350)

8 (LNG IUS or LNG IUD).tw. (607)

9 Levonorgestrel-releasing intrauterine system\$.tw. (494)

10 Levonorgestrel-releasing intrauterine device\$.tw. (164)

11 (IUD\$ or Mirena).tw. (8243)

12 or/6-11 (11321)

13 Intrauterine Devices, Medicated/ae [Adverse Effects] (383)

14 exp Neoplasm Recurrence, Local/ (91623)

15 exp Endometrial Hyperplasia/ (3118)

16 exp Endometrial Neoplasms/ (16799)

17 exp Adenocarcinoma/ (308090)

18 exp Neoplasm Metastasis/ (168719)

19 exp Antineoplastic Agents, Hormonal/ae [Adverse Effects] (16203)

20 exp Tamoxifen/ae [Adverse Effects] (2944)

21 breast cancer recurrence\$.tw. (1065)

22 recurrent breast cancer.tw. (1245)

23 Local Neoplasm Recurrence\$.tw. (5)

24 secondary breast cancer $\$$.tw. (72)

25 secondary neoplasm\$.tw. (452)

26 secondary cancer\$.tw. (853)

27 Neoplasm Metastasis.tw. (74)

28 cancer metastasis.tw. (6717)

29 advanced breast cancer.tw. (6880)

30 breast cancer survival.tw. (1012)

31 Endometrial Hyperplasia.tw. (2536)

32 Endometri\$ patholog\$.tw. (646)

33 Endometri\$ polyp\$.tw. (1202)

34 Endometrial adenocarcinoma\$s.tw. (2770)

35 endometrial cancer.tw. (11955)

36 or/13-35 (546313) 
375 and 12 and 36 (56)

\section{Appendix 6. EMBASE search (1980 to October 2015)}

1 exp breast tumor/ (388566)

2 (Breast cancer\$ or Breast Neoplasm\$).tw. (266249)

3 breast tumor\$.tw. (19642)

4 or/1-3 (416695)

5 exp intrauterine contraceptive device/ (14353)

6 Intrauterine Device\$.tw. (4807)

7 (LNG IUS or LNG IUD).tw. (926)

8 Levonorgestrel-releasing intrauterine system\$.tw. (647)

9 Levonorgestrel-releasing intrauterine device\$.tw. (202)

10 (IUD\$ or Mirena).tw. (7409)

11 or/5-10 (16901)

12 intrauterine contraceptive device/ae [Adverse Drug Reaction] (1458)

13 exp tumor recurrence/ (43045)

14 exp endometrium hyperplasia/ (6121)

15 exp endometrium tumor/ (44939)

16 exp breast adenocarcinoma/ or exp adenocarcinoma/ (84246)

17 exp metastasis/ (435415)

18 "antineoplastic hormone agonists and antagonists"/ae [Adverse Drug Reaction] (541)

19 exp tamoxifen/ae [Adverse Drug Reaction] (6669)

20 breast cancer recurrence $\$ . t w .(1657)$

21 recurrent breast cancer\$.tw. (1589)

22 Local Neoplasm Recurrence\$.tw. (5)

23 secondary breast cancer\$.tw. (132)

24 secondary neoplasm\$.tw. (602)

25 secondary cancer\$.tw. (1265)

26 Neoplasm Metastasis.tw. (83)

27 cancer metastasis.tw. (8860)

28 advanced breast cancer.tw. (9170)

29 breast cancer survival.tw. (1254)

30 Endometrial Hyperplasia.tw. (3303)

31 Endometri\$ patholog\$.tw. (961)

32 Endometri\$ polyp\$.tw. (1881)

33 Endometrial adenocarcinoma\$.tw. (3393)

34 endometrial cancer.tw. (16312)

35 or/12-34 (589755)

364 and 11 and 35 (164)

37 Clinical Trial/ (851926)

38 Randomized Controlled Trial/ (386357)

39 exp randomization/ (68465)

40 Single Blind Procedure/ (21150)

41 Double Blind Procedure/ (124284)

42 Crossover Procedure/ (44751)

43 Placebo/ (264658)

44 Randomi?ed controlled trial\$̦.tw. (125251)

45 Rct.tw. (18496)

46 random allocation.tw. (1460)

47 randomly allocated.tw. (23462)

48 allocated randomly.tw. (2066)

49 (allocated adj2 random).tw. (739)

50 Single blind\$.tw. (16466)

51 Double blind\$.tw. (155581)

52 ((treble or triple) adj blind\$).tw. (494)

53 placebo\$.tw. (222116)

54 prospective study/ (310814)

55 or/37-54 (1512736)

56 case study/ (34158)

57 case report.tw. (292453)

58 abstract report/ or letter/ (941185) 
59 or/56-58 (1261247)

6055 not 59 (1472739)

61 exp Meta Analysis/ (100433)

62 ((meta adj analy\$) or metaanalys\$).tw. (108700)

63 (systematic adj (review\$1 or overview\$1)).tw. (89312)

64 review.ti. (340162)

65 or/61-64 (470737)

6660 or $65(1842276)$

6736 and $66(69)$

\section{Appendix 7. CINAHL search (1982 to October 2015)}

\begin{tabular}{|c|c|c|}
\hline \# & Query & Results \\
\hline S14 & S6 AND S13 & 35 \\
\hline S13 & S7 OR S8 OR S9 OR S10 OR S11 OR S12 & 2,313 \\
\hline S12 & TX(IUD* or Mirena*) & 744 \\
\hline S11 & TX (Levonorgestrel-releasing intrauterine) & 175 \\
\hline S10 & TX (LNG IUD) & 15 \\
\hline S9 & TX (LNG IUS) & 78 \\
\hline S8 & TX Intrauterine Device ${ }^{\star}$ & 2,065 \\
\hline S7 & (MM "Intrauterine Devices") & 1,107 \\
\hline S6 & S1 OR S2 OR S3 OR S4 OR S5 & 61,738 \\
\hline S5 & TX (Breast cancer* or Breast Neoplasm*) & 61,494 \\
\hline S4 & TX (Breast cancer ${ }^{\star}$ or Breast Neoplasm*).tw & 1 \\
\hline S3 & TX breast tumour* & 451 \\
\hline S2 & TX breast tumor* & 2,002 \\
\hline S1 & (MM "Breast Neoplasms+") & 43,927 \\
\hline
\end{tabular}

\section{Appendix 8. PyscINFO (October 2015)}

1 exp Intrauterine Devices/ (91)

2 Levonorgestrel.tw. (62)

3 intrauterine device\$.tw. (174)

4 iud.tw. (131)

5 mirena.tw. (9)

6 intrauterine system\$.tw. (26)

7 exp Breast Neoplasms/ (7066) 
8 breast neoplasm\$.tw. (40)

9 breast tumor\$.tw. (73)

10 (breast adj5 ca).tw. (1)

11 (breast adj5 cancer\$).tw. (9414)

12 or/1-6 (303)

13 or/7-11 (9639)

1412 and $13(1)$

\section{Appendix 9. PubMed search (1946 to October 2015)}

(("Clinical Trial"[Publication Type]) OR ("Phase I Clinical Trial" OR "Phase II Clinical Trial" OR "Phase III Clinical Trial" OR "Phase IV Clinical Trial" OR "Controlled Clinical Trial" OR "Multicenter Study" OR "Randomized Controlled Trial" OR "Pragmatic Clinical Trial"))

AND

(("Breast Neoplasms"[Mesh] NOT "Breast Neoplasms, Male"[Mesh]) OR ("Breast cancer" OR "Breast Neoplasms"))

AND

(("Intrauterine Devices, Medicated"[Mesh]) OR ("Intrauterine Devices" OR "IUD" OR "Medicated Intrauterine Devices" OR "LNG IUS" OR "Levonorgestrel-releasing intrauterine system" OR "Mirena"))

AND

(("Intrauterine Devices, Medicated/adverse effects"[Mesh]) OR ("Neoplasm Recurrence, Local"[Mesh] OR "Breast Neoplasms/ secondary"[Mesh] OR "Neoplasms/secondary"[Mesh] OR "Endometrial Hyperplasia"[Mesh] OR "Endometrial Neoplasms"[Mesh] OR "Adenocarcinoma" [Mesh] OR "Neoplasm Metastasis"[Mesh] OR "Antineoplastic Agents, Hormonal/adverse effects"[Mesh] OR "Tamoxifen/ adverse effects"[Mesh]) OR ("breast cancer recurrence" OR "recurrent breast cancer" OR "Local Neoplasm Recurrence" OR "secondary breast cancer" OR "secondary neoplasms" OR "secondary cancers" OR "Neoplasm Metastasis" OR "cancer metastasis" OR "breast cancer metastasis" OR "advanced breast cancer" OR "breast cancer survival" OR "Endometrial Hyperplasia" OR "Endometrial pathology" OR "Endometrial polyps" OR "Endometrial adenocarcinoma" OR "endometrial cancer"))

\section{WHAT'S NEW}

\begin{tabular}{lll}
\hline Date & Event & Description \\
\hline 9 November 2015 & $\begin{array}{l}\text { New citation required but conclusions } \\
\text { have not changed }\end{array}$ & No changes to conclusions of this review. \\
\hline 9 November 2015 & New search has been performed & $\begin{array}{l}\text { Two new studies (Kesim 2008; Omar 2010) and a follow up of } \\
\text { two previously included studies (Chan 2007; Gardner 2000) were } \\
\text { identified for inclusion in this update. }\end{array}$ \\
\hline
\end{tabular}

\section{H I S T O R Y}

Protocol first published: Issue 3, 2008

Review first published: Issue 4, 2009

\begin{tabular}{lll}
\hline Date & Event & Description \\
\hline 20 September 2010 & Amended & Contact details updated. \\
& & New RCT included into review \\
\hline
\end{tabular}




\begin{tabular}{lll}
\hline Date & Event & Description \\
\hline 6 November 2008 & Amended & Converted to new review format \\
\hline 26 April 2007 & $\begin{array}{l}\text { New citation required and major } \\
\text { changes }\end{array}$ & Substantive amendment \\
\hline
\end{tabular}

\section{CONTRIBUTIONS OFAUTHORS}

Jason Chin: wrote the initial version of the 2009 review and updated it. Martha Hickey and Justin C Konje: revised and updated the first review.

Sally Dominick and H. Irene Su revised and updated the second review (2015). Martha Hickey and Jason Chin approved the draft updated review.

\section{DECLARATIONS OF INTEREST}

Former review author Professor Justin C Konje is a co-author for one of the randomised controlled trials included in this review (Gardner 2000).

\section{SOURCES OF SUPPORT}

\section{Internal sources}

- King Edward Memorial Hospital for Women, Western Australia, Australia.

- School of Women's and Infants' Health, Western Australia, Australia.

\section{External sources}

- Cochrane Menstrual and Subfertility Group, New Zealand.

Support of search strategy, advice and statistical analysis

\section{DIFFERENCES BETWEEN PROTOCOL AND REVIEW}

Updated methods according to MECIR standards.

\section{INDEX TERMS}

\section{Medical Subject Headings (MeSH)}

*Intrauterine Devices, Medicated; Adenocarcinoma [chemically induced] [prevention \& control]; Antineoplastic Agents, Hormonal [adverse effects]; Breast Neoplasms [ ${ }^{*}$ prevention \& control]; Chemotherapy, Adjuvant; Contraceptive Agents, Female [administration \& dosage]; Endometrial Hyperplasia [chemically induced] [ ${ }^{*}$ prevention \& control]; Endometrial Neoplasms [chemically induced] [ ${ }^{*}$ prevention \& control]; Levonorgestrel [ ${ }^{\star}$ administration \& dosage]; Neoplasm Recurrence, Local [prevention \& control]; Polyps [chemically induced] [prevention \& control]; Randomized Controlled Trials as Topic; Tamoxifen [adverse effects]

\section{MeSH check words}

Female; Humans 